\title{
ТАКСОНОМИЧЕСКИЕ РЕВИЗИИ И КОЛЛЕКЦИОННЫЕ БАЗЫ ДАННЫХ В ЭПОХУ ИНТЕРНЕТА: ОПЫТ РАБОТЫ С БОГАТОЙ ВИДАМИ ГРУППОЙ НАСЕКОМЫХ
}

\author{
(C) 2019 г. Ф. В. Константинов, ${ }^{1,2^{* *}}$ А. А. Намятова ${ }^{3 * *}$ \\ ${ }^{1}$ Санкт-Петербургский государственный университет \\ Университетская наб., 7/9, С.-Петербург, 199034 Россия \\ 2 Зоологический институт РАН \\ Университетская наб., 1, С.-Петербург, 199034 Россия \\ *e-mail: f.konstantinov@spbu.ru \\ ${ }^{3}$ Всероссийский научно-исследовательский институт защиты растений РАН \\ Подбельского ш., 3, Пушкин, С.-Петербург, 196608 Россия \\ **e-mail: anna.namyatova@gmail.com \\ Поступила в редакцию 28.04.2019 г. \\ После доработки 11.05.2019 г. \\ Принята к публикации 11.05.2019 г.
}

Сформированные в ходе трех столетий исследований и сборов энтомологические коллекции музеев мира - ключ к пониманию биоразнообразия и бесценные прямые сведения о распространении и биологии насекомых. Однако значительная часть коллекционных фондов остается не каталогизированной и, соответственно, недоступной для полноценного анализа. Таксономические ревизии любой группы животных или растений подразумевают синтез всей информации о таксоне. Этот синтез значительно выиграет от использования всех современных информационных технологий. Реляционная база данных экземпляров Arthropod Easy Capture (AEC) - удобный инструмент хранения и обобщения данных. Наш многолетний опыт ее использования при подготовке таксономических ревизий может служить иллюстрацией значительного упрощения работы над ревизиями и описаниями видов за счет ускорения работы с этикеточными данными, быстрого построения карт распространения, компиляции данных о кормовых растениях и обеспечения легкого доступа к первичным данным для других исследователей. Кроме того, база данных музейных экземпляров предоставляет обширные возможности для биогеографических и коэволюционных исследований.

Ключевые слова: базы данных, энтомологические коллекции, систематика, кибертаксономия, ревизии, биогеография, кормовые связи.

DOI: $10.1134 / \mathrm{S} 0367144519020102$

Роль таксономических коллекций в биологических исследованиях невозможно переоценить. Это ключевой источник информации о животных и растениях настоящего и прошлого, незаменимый в таксономических, эволюционных и биогеографических исследованиях, прикладных работах по сохранению биоразнообразия и анализу распространения адвентивных видов (Vollmar et al., 2010; Blagoderov et al., 2012; Bik, 2017). 
Стремительное развитие цифровых технологий в последние 25 лет кардинально изменило стиль работы систематиков. Быстрее и проще стали поиск и анализ необходимой литературы, получение и обработка высококачественных изображений внешнего вида и деталей строения, создание описаний таксонов и многие другие аспекты таксономической работы. Определение, описания, ревизии, синтез информации в монографиях, аннотированных списках флоры и фауны, интерпретация данных в свете филогенетических и биогеографических гипотез стали значительно эффективнее благодаря развитию биоинформационных технологий. Появились и совершенно новые возможности, в частности, связанные с анализом больших массивов данных оцифрованных музейных коллекций в экологических и эволюционных исследованиях (Soltis, Soltis, 2016), 3D моделированием (Ströbel et al., 2018) и многими другими формами работы.

Неудивительно, что проекты по оцифровке коллекционных материалов стали появляться практически одновременно с рождением соответствующих цифровых технологий (Peterson et al., 2010). Для ведения и организации коллекций и предоставления онлайн-доступа к оцифрованным данным разработано немало приложений, например, Arctos (https://arctosdb.org/), Arthropod Easy Capture (https://sourceforge.net/projects/ arthropodeasy/), EMu (https://emu.axiell.com/), Papis (http://www.papis.dk/), SilverBiology (http://www.silverbiology.com/), Specify (https://www.sustain.specifysoftware.org/), Symbiota (http://symbiota.org/). Естественно, оцифрованная база данных отдельного музея лишь в редких случаях может хранить исчерпывающую информацию по тому или иному таксону, что делает критически важными стандартизацию данных и их объединение на сайтах-агрегаторах. Практически универсально используемым в коллекционных базах стал стандарт Darwin Core (https://dwc.tdwg.org/), а основными агрегаторами - Global Biodiversity Information Facility (GBIF, https://www.gbif.org/) и Integrated Digitized Biocollections (iDigBio, https:/www.idigbio.org/), содержащие информацию об обширном материале из 1143 учреждений (Funk, 2018).

Тем не менее, бо́льшая часть относящихся к коллекционным экземплярам данных остается неоцифрованной и, соответственно, недоступной для полноценного анализа (Blagoderov et al., 2012). При этом охват отдельных таксонов и музеев электронными базами данных остается крайне неравномерным. Число хранящихся в естественнонаучных музеях мира экземпляров оценивают в 1.2-2.0 миллиарда единиц хранения (Ariño, 2010), при этом насекомые, в отличие от позвоночных, представлены в базах данных крайне фрагментарно. Так, только 7 \% доступных через GBIF в 2016 г. данных относятся к насекомым, притом что эта группа составляет более 75 \% видов и экземпляров в музейных коллекциях (Sikes et al., 2016).

Анонсированные в ряде крупных музеев амбициозные программы по оцифровке коллекционных фондов пока далеки от завершения. Так, в Музее естественной истории в Лондоне (Natural History Museum, London) в 2014 г. запущен проект по оцифровке каждого из 80 млн хранящихся здесь экземпляров животных и растений, рецентных и ископаемых. По данным портала музея (http://data.nhm.ac.uk/), к марту 2019 г. доступны онлайн записи о 4.25 млн. экз., что составляет чуть более 5 \% от общего числа единиц хранения. Нидерландская национальная коллекция в лейденском музее «Натуралис» (Naturalis Biodiversity Center, Leiden, the Netherlands) насчитывает 34 млн. единиц хранения, более половины из них составляют насекомые. Масштабная оцифровка всей коллекции началась в 2010 г., и к настоящему моменту обработано 4 млн. экз.(http://bioportal.naturalis.nl/). 
Можно условно выделить две основные стратегии при формировании коллекционных баз данных: работу с каждым экземпляром отдельно и фотографирование сразу целого энтомологического ящика или планшета с препаратами (Short et al., 2018).

Первый, традиционный подход к оцифровке коллекции (SLDC, specimen-level data capture) предполагает этикетирование каждого экземпляра уникальным идентификатором и последующий ручной ввод в базу данных таксономической, географической и другой относящейся к экземпляру информации. Реализовать его в сколько-нибудь приемлемые сроки для значительной по объему коллекции не представляется возможным даже при наличии значительных денежных средств, времени и множества специалистов. По оценке Шорта с соавт. (Short et al., 2018), за последние 20 лет таким образом было оцифровано менее 2 \% от общего числа хранящихся в музеях мира экземпляров насекомых. В то же время SLDC остается золотым стандартом при выборочной оцифровке части коллекции, например, отдельных таксонов, с которыми в данный момент работает исследователь, или типовых экземпляров.

Стремление к полной обработке всей коллекции «от стенки до стенки» в последние годы привело к интенсивному развитию второго подхода - фотографированию всего ящика (WDI, whole-drawer imaging). «Индустриальные» методы оцифровки предполагают использование специализированных сканеров, например SatScan (Mantle et al., 2012; Allan et al., 2019) или GigaPan (Bertone et al., 2012), для получения изображения всего ящика с насекомыми или лотка с препаратами в высоком разрешении с последующим распознаванием и каталогизацией отдельных экземпляров при помощи специализированного программного обеспечения, например Inselect (Hudson et al., 2015).

При всех преимуществах в скорости и экономичности подобная автоматизация несет и определенные риски. В любой естественнонаучной коллекции хранится немало неопределенного или неправильно определенного материала. Так, из 4500 экз. африканского рода растений Aframomum (Zingiberaceae), хранящихся в 40 гербариях 21 страны, 58 \% оказались определены только до рода или неправильно (Goodwin et al., 2015). Сходным образом при подготовке ревизии рода Euscelidia Westwood (Diptera, Asilidae) оказалось, что только 26 \% экземпляров в коллекциях мира были определены до вида, причем 83 \% из них - неверно (Meier, Dikow, 2004). Использование некритично оцифрованных коллекционных данных при моделировании экологической ниши, биогеографическом анализе и в любых других исследованиях, оперирующих «большими данными», может привести к значительным ошибкам (Peterson et al., 2010).

В отечественных музеях проекты полной оцифровки коллекционных фондов выглядят заведомо нереалистичными. Однако ничто не препятствует оцифровке коллекций и активному использованию новых информационных технологий в повседневной таксономической практике, например, при подготовке ревизий, определительных таблиц или обобщении данных о распространении.

Хотя практически все современные издания доступны в электронной форме, они во многом сохраняют традиционную для бумажных версий структуру, а подготовка статей порой не сильно отличается от традиций доцифровой эпохи (Clark et al., 2008; Miller et al., 2012). В частности, перечни исследованного материала, включая места сборов, чаще всего набираются в текстовом виде и каждый раз заново, практически так же, как во времена печатных машинок. При этом поиск координат мест сбора, нередко общих для разных групп организмов, проводится каждым автором независимо, 
а карты распространения публикуются в виде растровых изображений, что затрудняет их использование другими учеными. Иллюстрации диагностических признаков и другая сопутствующая информация чаще всего доступны читателю лишь в характерных для pdf-файлов объеме и разрешении, хотя дополнительные материалы легко предоставить, разместив их в соответствующих электронных ресурсах (см., например, Ang et al., 2013; Miller et al., 2014).

Таксономические ревизии любой группы животных или растений подразумевают синтез всей информации о таксоне. Этот синтез значительно выиграет от использования современных информационных технологий и сделает результаты доступными для биологов других специальностей, а таксономию - по-настоящему междисциплинарной (Meier, Dikow, 2004; Johnson, 2007; Beaman, Celinese, 2012; Bik, 2017; Funk, 2018; Short et al., 2018). Данный подход, получивший название «кибертаксономия» (Wheeler, 2007; Miller et al., 2012), благодаря сочетанию традиционных таксономических целей с современными цифровыми технологиями, получает все большее развитие в современной таксономической литературе. Представленная статья основана на многолетнем опыте ведения иллюстрированной и доступной в Интернете базы данных по ревизуемым группам клопов-слепняков (Heteroptera: Miridae) и может продемонстрировать преимущества кибертаксономического подхода в таксономических исследованиях.

\section{КЛОПЫ-СЛЕПНЯКИ (HETEROPTERA: MIRIDAE) КАК МОДЕЛЬНАЯ ГРУППА}

Клопы-слепняки (Heteroptera: Miridae) - крупнейшее и всесветно распространенное семейство настоящих полужесткокрылых, насчитывающее более 11000 видов (Cassis, Schuh, 2012). Среди насекомых с неполным превращением это семейство уступает по числу видов только цикадкам (Cicadellidae). Слепняки заселяют все ярусы растительных сообществ и играют большую роль как фито-, зоо- и фитозоофаги. Среди фитофагов в этом семействе есть серьезные вредители сельскохозяйственных культур и лесных насаждений. Слепняки - теплолюбивая группа, в типичных биоценозах Средней Азии и Кавказа составляющая около половины общего числа видов полужесткокрылых насекомых. Эволюционный успех группы, очевидно, во многом обусловлен тесными трофическими связями и параллельной эволюцией с семенными растениями. Виды ряда крупных и распространенных почти исключительно в высокогорьях и среднегорьях Кавказа и Средней Азии мирмекоморфных таксонов, таких как роды Myrmecophyes Fieber и Scirtetellus Reuter, имеют небольшие ареалы с повторяющимися паттернами распространения и превосходно подходят для анализа с позиций викариантной биогеографии. Таким образом, слепняки могут служить хорошей модельной группой при описании значительной части разнообразия биоты в наземных экосистемах и использоваться в широком круге исследований общебиологического характера, прежде всего эволюционных, биогеографических и экологических.

Решение теоретических вопросов в области зоогеографии, филогении и эволюции требует прежде всего знания видового состава систематической группы организмов в пределах природного региона. В то же время степень изученности как палеарктической, так и мировой фауны клопов-слепняков оставляет желать лучшего. Трудности в исследовании этой группы обусловлены огромным числом видов, отсутствием адекватных диагнозов многих родов, значительным полиморфизмом ряда видов и сложностью видовой диагностики. Достаточно отметить, что только за последние 20 лет в мировой фауне было описано чуть менее 1000 новых видов этого семей- 
ства (Schuh, 1995; Cassis, Schuh, 2012). При этом многие, особенно опубликованные в XIX - первой половине XX в. таксономические статьи представляют собой описания, выполненные без четкого видового диагноза и обоснования родовой принадлежности. Соответственно, определение даже до родового уровня по разрозненным описаниям нередко оказывается затруднительным, часть видов известна только по типовой серии, их распространение и кормовые связи исследованы лишь фрагментарно. Слепняки Палеарктики изучены лучше, чем в других регионах, однако и здесь сравнительно хорошо известна только довольно бедная фауна Северной и Центральной Европы. Однако Miridae - теплолюбивая группа, и в то время как для всей европейской части России, включая Предкавказье, известно 386 видов, для фауны Средней Азии в настоящее время приведено более 700 видов клопов-слепняков (Kerzhner, Josifov, 1999; Konstantinov, Namyatova, 2008, 2009).

Разносторонний анализ материала по значительному числу видов - трудная задача, и многие исследователи ограничивают работу изучением региональных фаун, что приводит к обильной синонимии на видовом и родовом уровнях (Schuh et al., 1995; Schuh, 2001; Konstantinov, 2016). Выходом из сложившейся ситуации могут стать последовательное выявление монофилетических групп надродового и родового ранга и их полные ревизии. Выполнение подобных масштабных исследований можно проводить гораздо быстрее, если обеспечить легкий доступ к результатам работы широкому кругу исследователей путем создания доступной через Интернет базы данных.

Традиционные таксономические описания зачастую недостаточны для уверенного определения видовой принадлежности экземпляров без исследования типовой серии. В связи с этим наш подход предполагает создание детальных и структурированных описаний, всегда снабженных подробными иллюстрациями всех таксономически важных структур как самцов, так и самок. Иллюстративный материал включает цифровые фотографии и изображения, полученные с помощью сканирующего электронного микроскопа, в высоком качестве доступные не только в напечатанной версии статьи, но и в Интернете.

\section{БАЗА ДАННЫХ ЭКЗЕМПЛЯРОВ ЭНТОМОЛОГИЧЕСКОЙ КОЛЛЕКЦИИ}

Используемая нами база данных была создана в рамках масштабной программы Национального научного фонда США «Инвентаризация биоразнообразия планеты» (Planetary Biodiversity Inventory, PBI) в 2003-2008 гг. Проект под руководством Рэндалла Шу из Американского музея естественной истории (Randall Schuh, American Museum of Natural History) и Герасимоса Кассиса из Университета Нового Южного Уэльса (Gerasimos Cassis, University of New South Wales) был сфокусирован на таксономической обработке монофилетической группы, объединяющей два крупных подсемейства клопов-слепняков - Phylinae и Orthotylinae.

Приложение, в настоящее время носящее название Arthropod Easy Capture Specimen Database (AEC), было разработано как серверная, реляционная и многопользовательская база данных на основе MySQL с вводом данных через Интернет и написанном на языке РНР веб-интерфейсом (Cassis et al., 2007; Schuh et al., 2010; Schuh, 2012). Она была успешно использована при обработке коллекций подсемейств Phylinae и Orthotylinae Американского музея естественной истории, Национальной коллекции Канады, Австралийского музея в Сиднее и других ведущих музеев мира в рамках проекта РВІ и постоянно дополняется международным коллективом гемиптерологов при 
работе над таксономическими проектами по слепнякам и другим семействам полужесткокрылых. Участвуя в проекте PBI, авторы данной статьи использовали базу данных при обработке фондовой коллекции Phylinae и Orthotylinae Зоологического института РАН (ЗИН), введя в нее информацию о 92000 экземпляров, относящихся к этим подсемействам.

Это же приложение стало основой при создании базы данных Apoidea Американского музея естественной истории (https:/www.amnh.org/our-research/invertebratezoology/resources/collections-databases/bee-database-project), трофической базы данных Северной Америки по растениям, их фитофагам и паразитоидам (Tri-Trophic Thematic Collection Network, http://tcn.amnh.org/) и в ряде других проектов. AЕC - программное обеспечение с открытым исходным кодом, доступное для скачивания и использования (https://sourceforge.net/projects/arthropodeasy/). Структура базы данных AEC описана в статьях Шу с соавт. (Schuh et al., 2010; Schuh, 2012), и в этой статье мы остановимся лишь на основных ее особенностях.

При создании и последующем ведении коллекционной базы данных необходимо предусмотреть возможность изменения и дополнения информации по каждому экземпляру и, наоборот, быстрого поиска уже введенной информации в общем массиве базы данных. Соответственно, экземпляр должен быть снабжен небольшой этикеткой - уникальным идентификатором экземпляра (USI, unique specimen identifier). В нашем случае каждая уникальная этикетка имеет 16-значный цифро-буквенный код, дублированный машиночитаемым баркодом (рис. 1, 2). Музейные коды для каждого экземпляра довольно давно используется исследователями позвоночных, палеонтологами и, отчасти, ботаниками (Schuh, 2012), но пока это не стало стандартом в энтомологических работах, в значительной степени из-за обширности коллекционных фондов насекомых. Тем не менее, наличие уникального кода - единственный способ надежной связи конкретного экземпляра со всей информацией о нем, будь то полевые записи, особенности биологии, секвенированные последовательности ДНК, фотографии или рисунки деталей строения.

База данных АЕС имеет три основных пользовательских веб-интерфейса: это режимы ввода данных (museum mode), редактирования (edit mode) и отчета (report mode). Первый режим (рис. 3) подразделен на 5 независимо заполняемых блоков: таксономическая информация (taxon information), место сбора (locality information), дата сбора и имя сборщика (collection event), информация о конкретном экземпляре (specimen information), хозяевах или кормовых растениях (host information). Блочная организация веб-интерфейса значительно ускоряет ввод данных. Так, при введении в базу данных серии экземпляров одного вида с идентичными этикеточными и другими относящимися к сбору данными достаточно набрать в соответствующие поля первый и последний номер USI-этикеток серии. Изменение любого параметра у следующего вносимого в базу данных экземпляра, например, даты сбора, определения или кормового растения, не потребует изменения заполненных для предыдущих экземпляров полей. Более того, организация реляционной базы данных предполагает однократный ввод большей части информации, такой как название вида, место сбора, дата и фамилия сборщика, кормовое растение и др. Например, любая уже имеющаяся в базе точка сбора может быть быстро найдена с помощью опции «find locality» и автоматически подставлена в соответствующие поля. 
Подавляющее большинство экземпляров из коллекции ЗИН было этикетировано без указания координат места сбора, и нередко их поиск сопряжен со значительными сложностями. Тем не менее, мы старались найти и внести в базу данных координаты во всех случаях, когда это было возможно. Этот подход требует значительной затраты времени на начальном этапе, но значительно упрощает и ускоряет работу в дальнейшем, особенно по сравнению с традиционным перепечатыванием этикеточных данных в таксономических ревизиях, не предполагающим возможности повторного использования данных. Точки сбора палеарктических клопов-слепняков из фондовой коллекции ЗИН показаны на рис. 4.

Режим редактирования (рис. 5) предоставляет удобный доступ ко всем вхождениям базы данных. Это позволяет быстро редактировать и дополнять формы для отдельных экземпляров или их групп, отвечающих критерию поиска, добавлять фотографии внешнего вида или отдельных структур, данные о секвенированных последовательностях ДНК, результаты измерений и другую информацию об экземплярах. Сходным образом этот режим позволяет вносить изменения и дополнения в формы таксономических данных, мест и дат сбора, хозяев, сборщиков и другую информацию.

Режим отчета позволяет пользователям создавать сложные запросы по всему массиву данных. Один из вариантов подобного запроса представлен на рис. 6. Так как одной из важных задач, стоявших перед создателями базы данных, было упрощение и ускорение подготовки таксономических ревизий, режим отчета позволяет автоматически генерировать списки исследованного материала по каждому виду в нескольких вариантах форматирования (рис. 7) и сразу помещать их в статью. Предусмотрены также вывод координат мест сбора нужного в данный момент таксона в формате, используемом всеми основными картографическими приложениями, автоматическое создание и вывод на печать нужных географических этикеток и другие упрощающие работу систематика функции.

\section{ИСПОЛЬЗОВАНИЕ БАЗЫ В ПОВСЕДНЕВНОЙ ТАКСОНОМИЧЕСКОЙ ПРАКТИКЕ И ОТОБРАЖЕНИЕ ДАННЫХ В ИНТЕРНЕТЕ}

Описанные выше архитектура и возможности AЕC базы данных доступны работающим с ней пользователям, имеющим права доступа. Однако одна из основных целей работы с ней заключается в доступности данных для использования систематиками, биогеографами и экологами. Свободное получение первичной информации и визуализация данных из базы АЕС реализованы несколькими способами.

Во-первых, данные становятся мгновенно доступными через интерфейс сайта Heteroptera Species Pages (http://research.amnh.org/pbi/heteropteraspeciespage/), где для отображения всех данных и иллюстраций по конкретному виду достаточно ввести видовое название в поисковую строку. Во-вторых, данные АЕС периодически экспортируются и становятся доступными через интерфейс сайта Discover Life (https://www. discoverlife.org/), обладающего удобными и интуитивно понятными возможностями по отображению обобщенных html-страниц, фотографий и карт распространения для каждого вида.

Подготовленные нами на протяжении последних 10 лет таксономические ревизии отдельных таксонов из подсемейств Phylinae и Orthotylinae (например, Konstantinov, 2008a, 2008b, 2008e; Namyatova, Konstantinov, 2009; Namyatova 2010; Konstantinov, Vinokurov, 2011), а также других подсемейств клопов-слепняков (Konstantinov, 


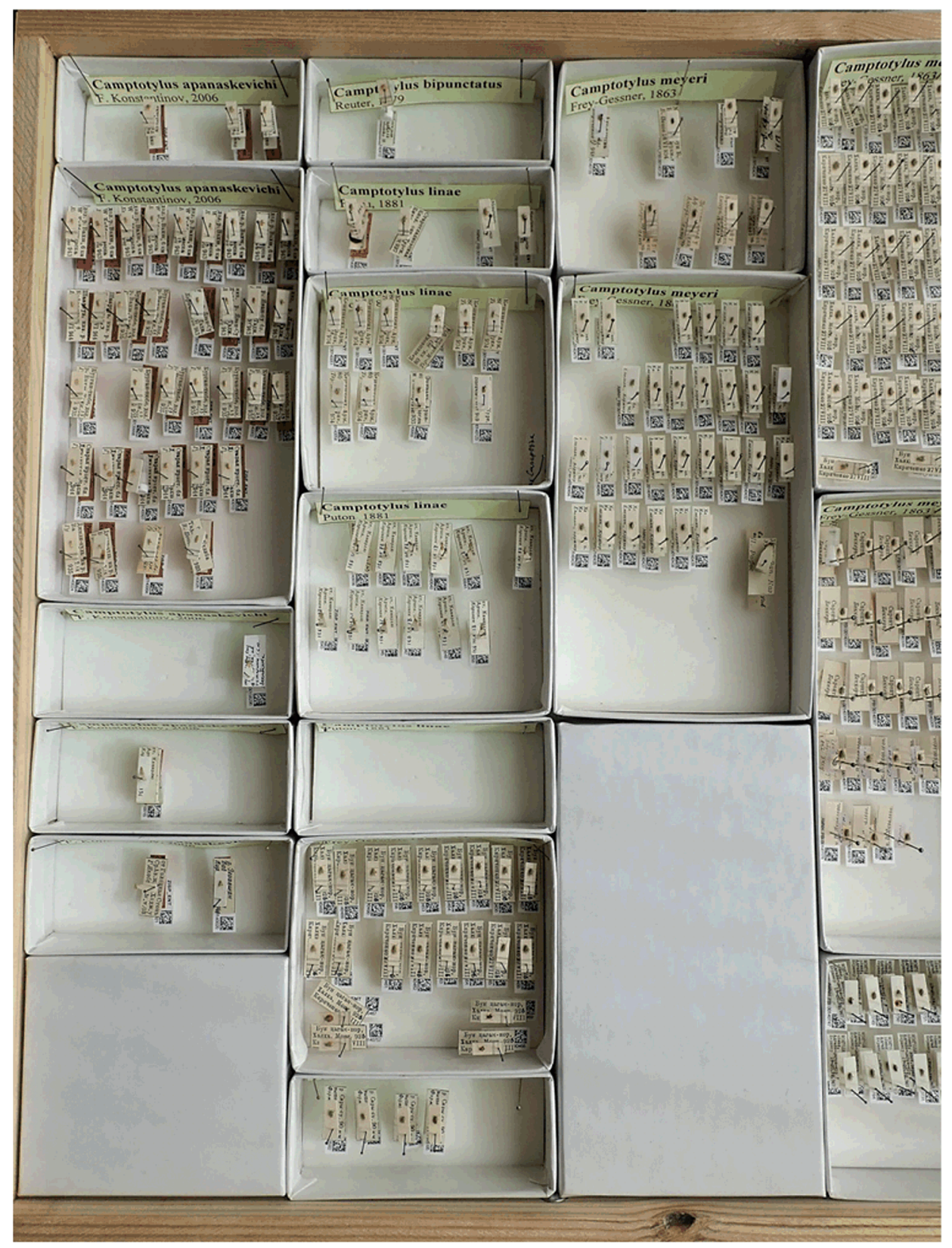

Рис. 1,2 . Использование этикеток с машиночитаемыми кодами при подготовке ревизии рода Camptotylus Fieber (Konstantinov, 2008a).

1 - общий вид коллекционного ящика ЗИН, 2 - серия экземпляров с USI-этикетками. 


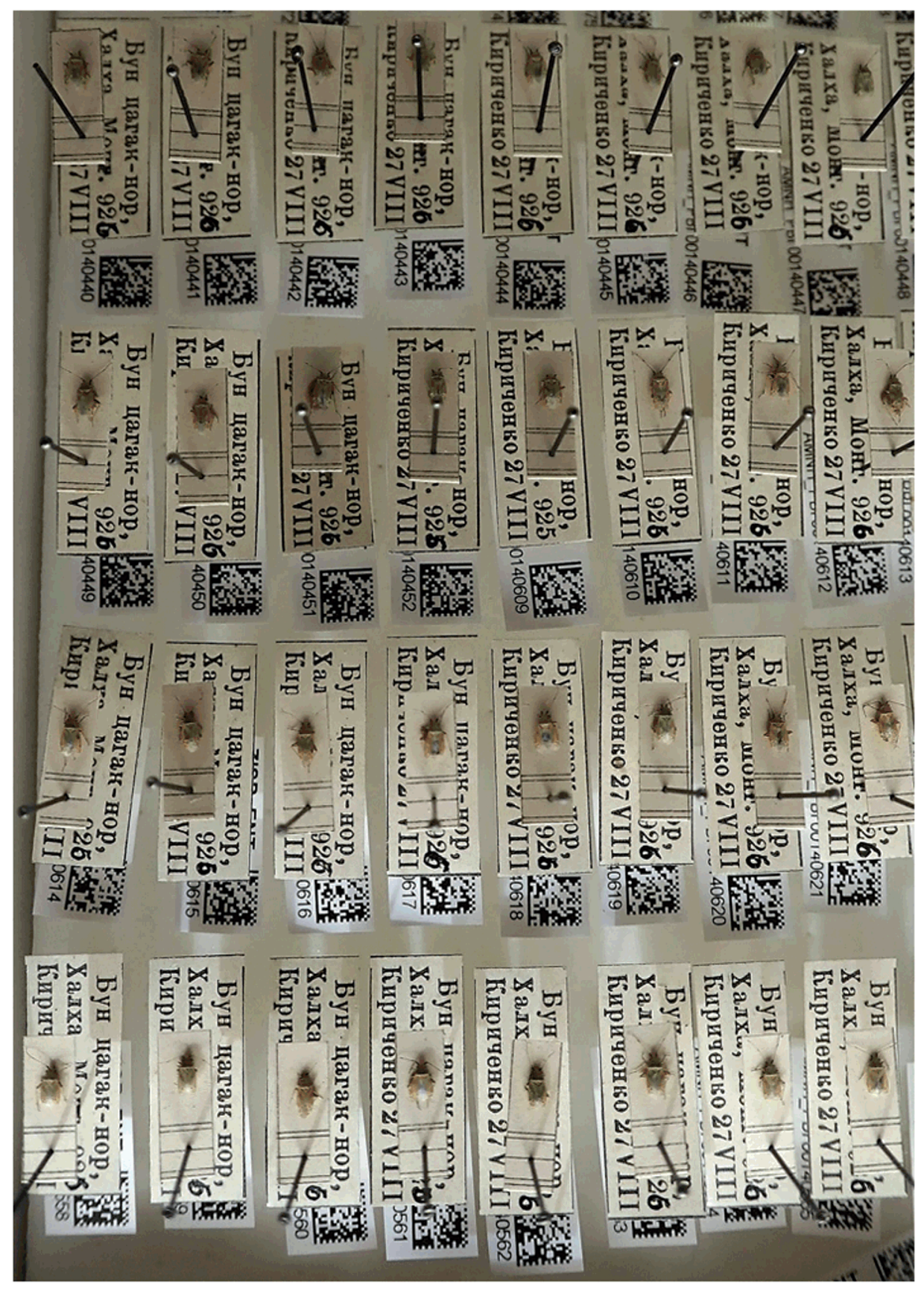

Рис. 1, 2 (продолжение). 


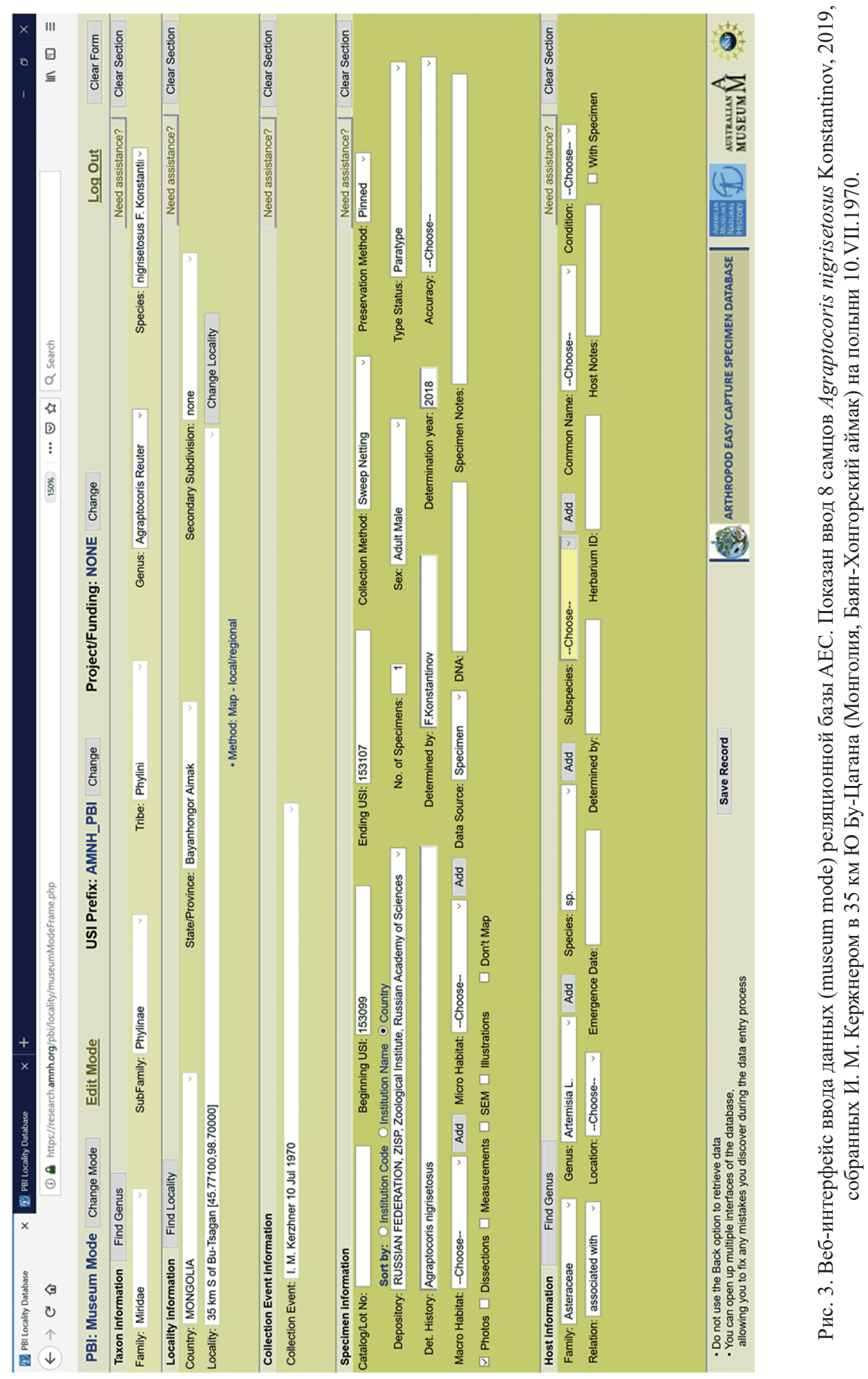



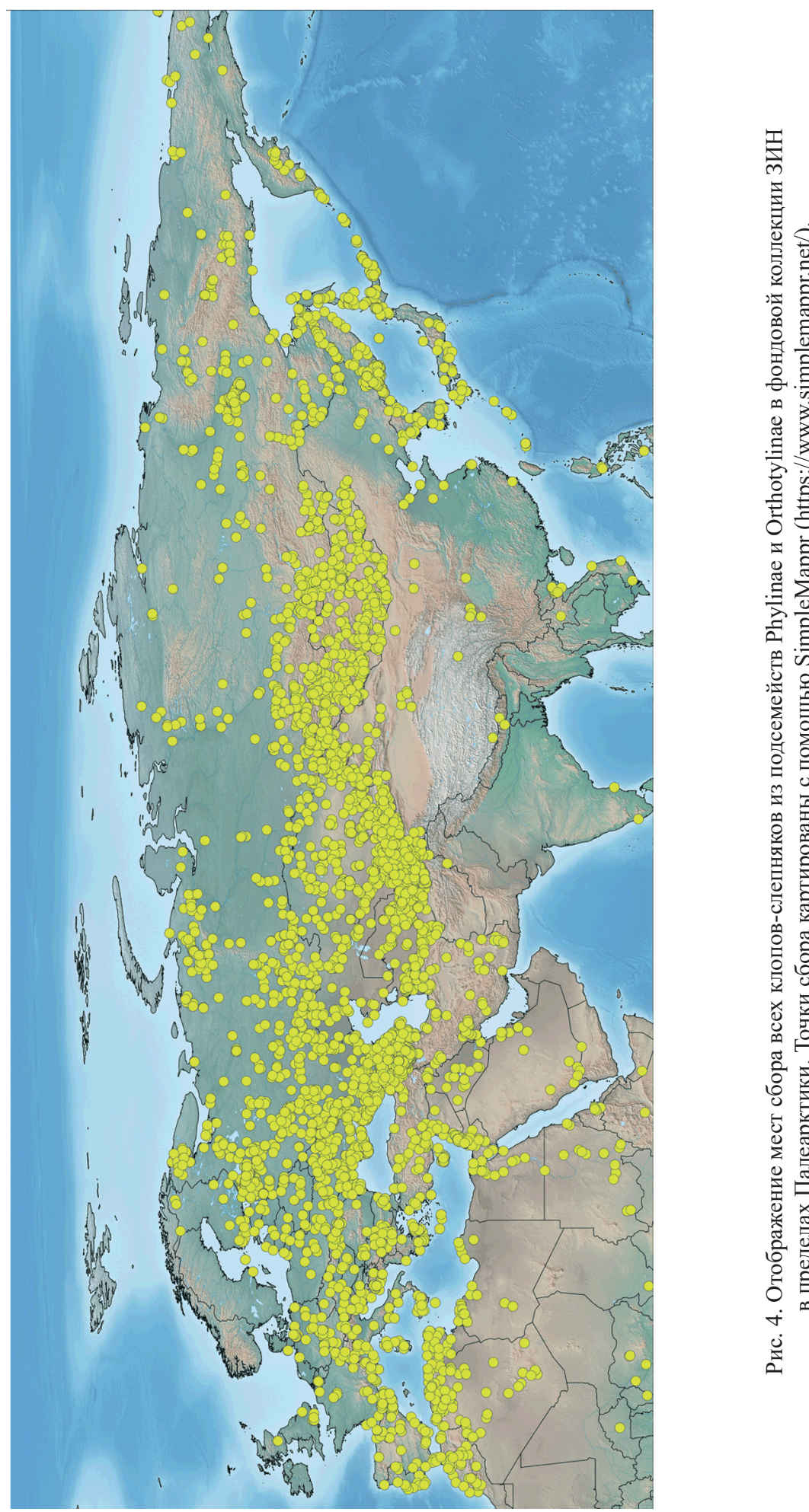


\begin{tabular}{|c|c|c|c|c|c|c|c|c|c|c|c|c|c|c|}
\hline \multicolumn{15}{|l|}{ (6) PBI Locality Database } \\
\hline$\leftarrow \rightarrow c$ 甶 & \multicolumn{14}{|c|}{ (1) Antps://research.amnh.org/pbi/locality/specimenList2.php?FamilyuID=6296\&:GenuSUID=6203\&:SpeciesUID =81807\&:Search=Search } \\
\hline $\begin{array}{l}\text { PBI: Edit Mode } \\
\text { Change Mode }\end{array}$ & \multicolumn{14}{|c|}{ Specimen [by taxon; add USI] [Need assistance?] } \\
\hline \multirow{2}{*}{$\begin{array}{l}\text { Specimen [searchl } \\
\text { Specimen } \\
\text { by taxon; add USI] }\end{array}$} & Family & \multicolumn{2}{|c|}{ Miridae } & $\because$ & Genus & \multicolumn{4}{|c|}{\begin{tabular}{|l|l|l} 
Solenoxyphus [Phylini $\mathrm{PI} \sim$ & Species \\
\end{tabular}} & \multicolumn{2}{|c|}{ kazakhstanicus } & \multicolumn{2}{|c|}{$\square$ View Specimens without USI } & Search \\
\hline & $\Sigma=28$ & $=28$ & & & \multicolumn{2}{|c|}{ Toggle All } & \multicolumn{3}{|c|}{ Update } & \multicolumn{2}{|c|}{ Delete } & \multicolumn{2}{|l|}{ Print } & \\
\hline \multirow{2}{*}{$\begin{array}{l}\text { Taxon } \\
\text { Habitat } \\
\text { Host } \\
\text { Locality } \\
\text { Locality [search] }\end{array}$} & & UID & USI & Sex & Type & D & $\mathrm{I} \mid \mathrm{M}$ & $P$ & Country & \begin{tabular}{|l} 
State/ \\
Prov.
\end{tabular} & \begin{tabular}{|l|} 
Sec. \\
Subdiv. \\
\end{tabular} & Locality & \begin{tabular}{|l|}
$\begin{array}{l}\text { Collection } \\
\text { Event }\end{array}$ \\
\end{tabular} & Images \\
\hline & $\square$ & $\begin{array}{c}1501717 \\
\# 1\end{array}$ & $\begin{array}{l}\text { AMNH_PBI } \\
00155871\end{array}$ & \begin{tabular}{|l} 
Adult \\
Male
\end{tabular} & \multicolumn{2}{|c|}{ Paratype } & & KAZAKHSTAN & $\begin{array}{l}\text { Karaganda } \\
\text { Prov. }\end{array}$ & none & $\begin{array}{l}30 \mathrm{~km} \mathrm{NW} \text { of } \\
\text { Dzhezkazgan } \\
{[47.90000,68.05000]} \\
541 \mathrm{~m}(1775 \mathrm{ft})\end{array}$ & $\begin{array}{l}\text { 04 Jun } \\
1962, \text { I. M. } \\
\text { Kerzhner }\end{array}$ & 刍 \\
\hline $\begin{array}{l}\text { Collection Event } \\
\text { Field Host } \\
\text { Field Images }\end{array}$ & $\square$ & $\frac{1501718}{\# 2}$ & $\begin{array}{l}\text { AMNH_PBI } \\
00155872\end{array}$ & \begin{tabular}{|l} 
Adult \\
Male
\end{tabular} & \multicolumn{2}{|c|}{ Paratype } & & $\mathbf{P}$ & KAZAKHSTAN & \begin{tabular}{|l} 
Karaganda \\
Prov.
\end{tabular} & none & $\begin{array}{l}30 \mathrm{~km} \text { NW of } \\
\text { Dzhezkazgan } \\
{[47.90000,68.05000]} \\
541 \mathrm{~m}(1775 \mathrm{ft}) \\
\end{array}$ & $\begin{array}{l}04 \text { Jun } \\
1962, \text { I. M. } \\
\text { Kerzhner }\end{array}$ & (8) 후 \\
\hline $\begin{array}{l}\text { Country } \\
\text { State/Province } \\
\text { Sec. Subdivision }\end{array}$ & \multicolumn{2}{|c|}{\begin{tabular}{|c|c|}
$\square$ & 1501699 \\
& $\# 3$
\end{tabular}} & $\begin{array}{l}\text { AMNH_PBI } \\
00155841\end{array}$ & \begin{tabular}{|l|} 
Adult \\
Female
\end{tabular} & \multicolumn{2}{|c|}{ Paratype } & & \multicolumn{2}{|r|}{ KAZAKHSTAN } & \begin{tabular}{|l|} 
West \\
Kazakhstan \\
Prov.
\end{tabular} & none & \begin{tabular}{|l|} 
At the confluence of \\
Karakengir and Zhezdy \\
Streams \\
{$[47.46666,67.95000]$}
\end{tabular} & $\begin{array}{l}24 \text { May } \\
1962 \text {, I. M. } \\
\text { Kerzhner }\end{array}$ & 艄 \\
\hline $\begin{array}{l}\text { Institution } \\
\text { Collector/Donor } \\
\text { Log out }\end{array}$ & $\square$ & $\begin{array}{c}\frac{1501700}{\# 4} \\
4\end{array}$ & $\begin{array}{l}\text { AMNH_PBI } \\
00155843\end{array}$ & \begin{tabular}{|l|} 
Adult \\
Female
\end{tabular} & Paratype & & & & KAZAKHSTAN & \begin{tabular}{|l|} 
West \\
Kazakhstan \\
Prov.
\end{tabular} & none & $\begin{array}{l}\text { At the confluence of } \\
\text { Karakengir and Zhezdy } \\
\text { Streams } \\
{[47.46666,67.95000]}\end{array}$ & $\begin{array}{l}24 \text { May } \\
1962, \text { I. M. } \\
\text { Kerzhner }\end{array}$ & 粯 \\
\hline & $\square$ & $\begin{array}{c}1501701 \\
\# 5\end{array}$ & $\begin{array}{l}\text { AMNH_PBI } \\
00155844\end{array}$ & \begin{tabular}{|l|} 
Adult \\
Female
\end{tabular} & Paratype & & & & KAZAKHSTAN & $\begin{array}{l}\text { West } \\
\text { Kazakhstan } \\
\text { Prov. }\end{array}$ & none & $\begin{array}{l}\text { At the confluence of } \\
\text { Karakengir and Zhezdy } \\
\text { Streams } \\
{[47.46666,67.95000]}\end{array}$ & $\begin{array}{l}24 \text { May } \\
1962 \text {, I. M. } \\
\text { Kerzhner }\end{array}$ & 驺 \\
\hline & $\square$ & $\begin{array}{c}1501702 \\
\# 6\end{array}$ & $\begin{array}{l}\text { AMNH_PBI } \\
00155847\end{array}$ & \begin{tabular}{|l|} 
Adult \\
Female
\end{tabular} & Paratype & & & & KAZAKHSTAN & $\begin{array}{l}\text { West } \\
\text { Kazakhstan } \\
\text { Prov. }\end{array}$ & none & $\begin{array}{l}\text { At the confluence of } \\
\text { Karakengir and Zhezdy } \\
\text { Streams } \\
{[47.46666,67.95000]}\end{array}$ & $\begin{array}{l}24 \text { May } \\
1962, \text { I. M. } \\
\text { Kerzhner }\end{array}$ & 堘 \\
\hline & $\square$ & $\begin{array}{c}1501703 \\
\# 7\end{array}$ & $\begin{array}{l}\text { AMNH_PBI } \\
00155848\end{array}$ & \begin{tabular}{|l|} 
Adult \\
Female
\end{tabular} & Paratype & & & & KAZAKHSTAN & $\begin{array}{l}\text { West } \\
\text { Kazakhstan } \\
\text { Prov. }\end{array}$ & none & $\begin{array}{l}\text { At the confluence of } \\
\text { Karakengir and Zhezdy } \\
\text { Streams } \\
{[47.46666,67.95000]}\end{array}$ & $\begin{array}{l}24 \text { May } \\
1962, \text { I. M. } \\
\text { Kerzhner }\end{array}$ & 勾 \\
\hline & $\square$ & $\begin{array}{c}1501704 \\
\# 8\end{array}$ & $\begin{array}{l}\text { AMNH_PBI } \\
00155849\end{array}$ & \begin{tabular}{|l|} 
Adult \\
Female
\end{tabular} & Paratype & & & & KAZAKHSTAN & $\begin{array}{l}\text { West } \\
\text { Kazakhstan } \\
\text { Prov. }\end{array}$ & none & $\begin{array}{l}\text { At the confluence of } \\
\text { Karakengir and Zhezdy } \\
\text { Streams } \\
{[47.46666,67.95000]}\end{array}$ & $\begin{array}{l}24 \text { May } \\
1962, \text { I. M. } \\
\text { Kerzhner }\end{array}$ & 堘 \\
\hline & $\square$ & $\frac{1501705}{1}$ & $\begin{array}{l}\text { AMNH_PBI } \\
00155850\end{array}$ & $\left|\begin{array}{l}\text { Adult } \\
\text { Female }\end{array}\right|$ & Paratype & D & & $\mathbf{P}$ & KAZAKHSTAN & $\begin{array}{l}\text { West } \\
\text { Kazakhstan }\end{array}$ & none & $\begin{array}{l}\text { At the confluence of } \\
\text { Karakengir and Zhezdy }\end{array}$ & $\begin{array}{l}24 \text { May } \\
1962, \text { I. M. }\end{array}$ & 8 औै \\
\hline
\end{tabular}

Рис. 5. Режим редактирования (edit mode) реляционной базы АЕС. Показан поиск экземпляров Solenoxyphus kazakhstanicus Konstantinov et Korzeev, введенных в базу данных при описании этого вида (Konstantinov, Korzeev, 2014). Иконка фотоаппарата в правой колонке показывает

наличие иллюстраций для данного экземпляра. Электронные формы в левом фрейме позволяют проводить поиск и редактировать таксономическую информацию, места сборов и любые другие типы вхождений.

Knyshov, 2015; Namyatova, Cassis, 2016a, 2016b, 2019; Namyatova et al., 2019), были выполнены с использованием базы данных АЕС. В каждом случае это не только упрощало работу с исследуемым материалом из разных музеев мира, анализом кормовых связей и картированием распространения, но и дало возможность предоставить расширенный доступ к материалам исследования всем пользователям.

В частности, все сделанные для исследованных видов высококачественные фотографии внешнего вида, электронограммы важных диагностических признаков и других необходимых для диагностики деталей строения, в том числе не вошедшие в публикацию, доступны в интернете в большем разрешении, чем у обычных пдф-файлов. Размещение цветных микрофотографий делает возможным использование ресурса в качестве виртуальной справочной коллекции, что значительно облегчит определение видов таксономически сложной группы.

Таксономическая ревизия рода Campylomma Reuter (Heteroptera: Phylinae) Западной Палеарктики (Konstantinov et al., 2015, 2016) может служить одним из множества примеров подобного подхода. Этот род включает в мировой фауне более 160 трудно различимых и полиморфных видов. Все сделанные в ходе работы фотографии внешнего вида и структур гениталий в разных проекциях для многих экземпляров из 


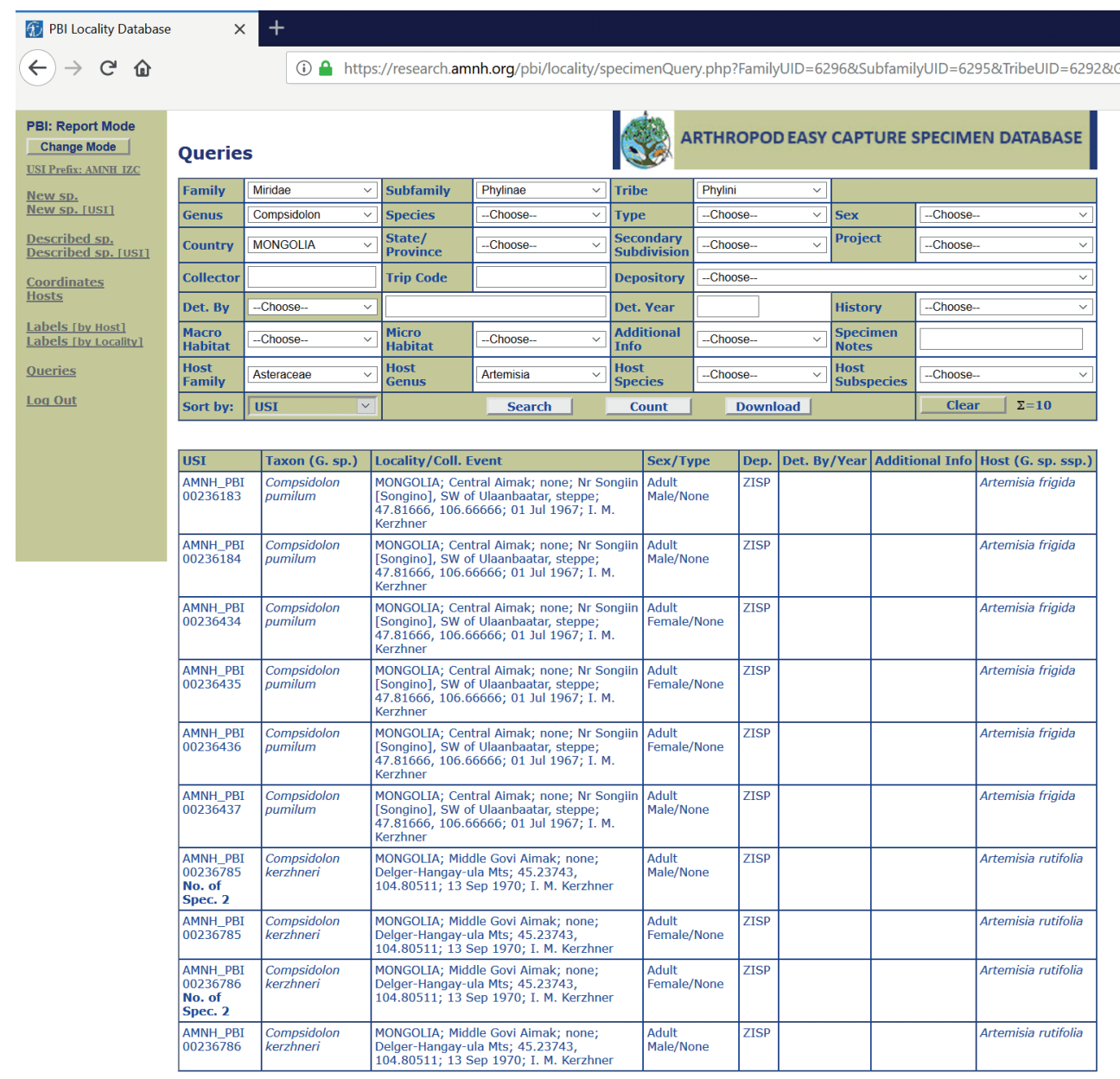

Total records, this query: 10

Total specimens, this query: 12

Рис. 6. Режим отчета (report mode) реляционной базы АЕС. Показан поиск всех видов и экземпляров клопов-слепняков рода Compsidolon Reuter (подсем. Phylinae) в коллекции ЗИН, собранных в Монголии на полыни.

разных частей ареала были загружены в базу данных и доступны в интернете. Так, по ссылке http://research.amnh.org/pbi/heteropteraspeciespage/speciesdetails.php?fromall= fromall\&speciesid=3209\&genusid=5790_можно посмотреть, как представлены данные по одному из исследованных видов, Campylomma verbasci (Meyer-Dür). Помимо этикеточных для каждого экземпляра приведены сведения о кормовых растениях и более 20 фотографий внешнего вида и важных для диагностики деталей строения. Аналогичным образом можно получить данные и по всем другим исследованным видам.

Точки сбора каждого вида приводятся с указанием координат, что позволяет автоматически генерировать масштабируемые карты распространения, получать и анализировать дополнительные данные, например, о трофических связях или стациальных предпочтениях. 


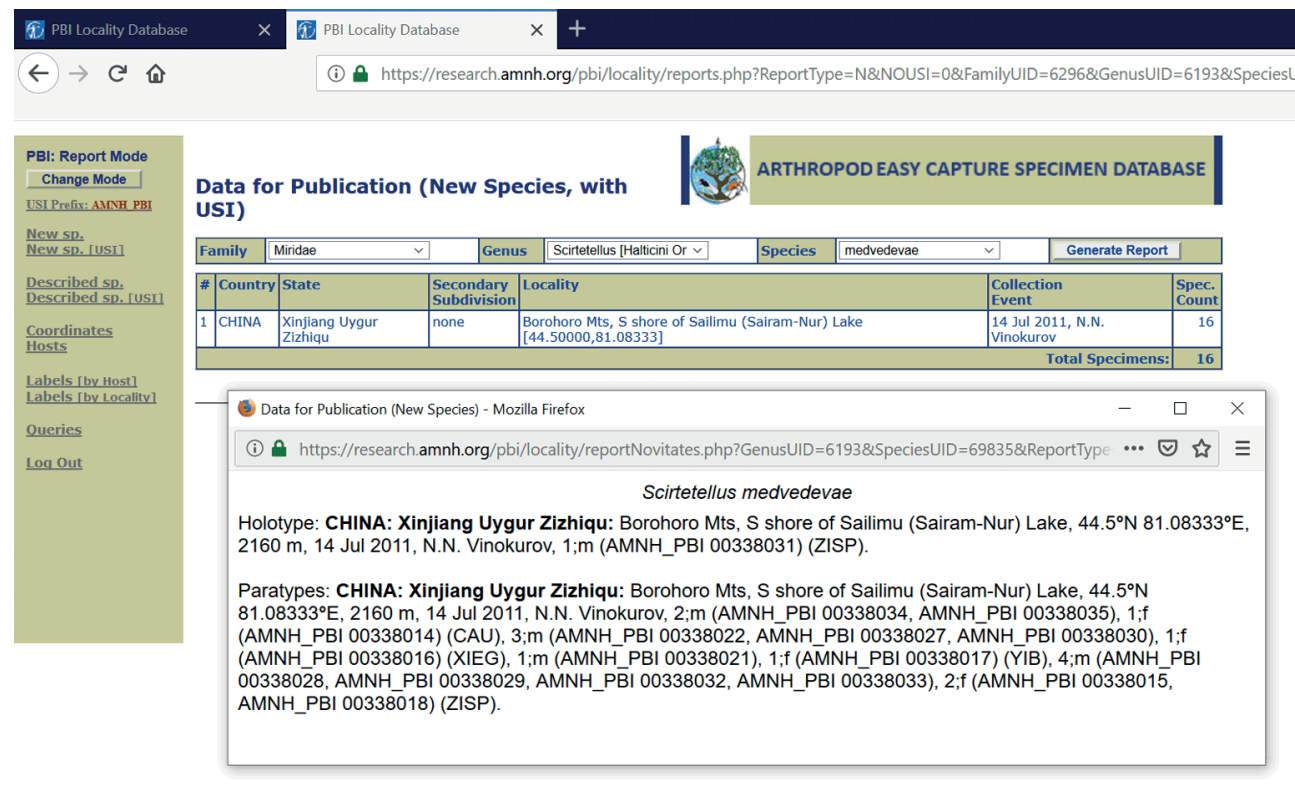

Рис. 7. Режим отчета (report mode) реляционной базы АЕС. Формирование списка исследованного материала при подготовке описания нового вида

Scirtetellus medvedevae Konstantinov (Konstantinov et al., 2013).

Координаты для каждого таксона можно легко извлечь в виде отдельного файла и использовать для картирования в специализированных программах, таких как ArcGis (например, Konstantinov, 2008c, 2008d; Namyatova et al., 2019), DIVA-GIS (например, Knyshov, Konstantinov, 2013a, 2013b), QGis (например, Konstantinov, Simov, 2018), или браузерных онлайн-приложениях, например Simplemappr (Konstantinov, 2019). В этих программах можно также составлять карты распространения видов, включая слои с экорегионами и климатическими поясами (Namyatova et al., 2019). Таким образом, пополняемая реляционная база по слепнякам может стать источником сведений для широкого круга исследователей и практиков.

\section{ВОЗМОЖНОСТИ АНАЛИЗА ДАННЫХ: КОРМОВЫЕ СВЯЗИ И РАСПРОСТРАНЕНИЕ}

Помимо результатов, полученных при подготовке таксономических ревизий, значительный интерес представляет и анализ обобщенного массива данных. Все данные по экземплярам подсемейств Phylinae и Orthotylinae из фондовой коллекции Зоологического института РАН были экспортированы из базы данных АЕС и загружены в среду программирования R (https://cran.r-project.org/bin/windows/base/) для дальнейшей обработки. Основой для дальнейшей работы стала фауна Палеарктики, превосходно представленная в коллекции ЗИН. Для этого региона известно более 1000 видов из 165 родов Phylinae и около 500 видов из 55 родов Orthotylinae (Kerzhner, Josifov, 1999), но регулярно выявляются и новые для науки таксоны (например, Namyatova, Konstantinov, 2009; Knyshov, Konstantinov, 2012; Konstantinov, Simov, 2018; Konstantinov, 2019). К настоящему времени в базу данных Arthropod Easy Capture занесена информация о 52699 экз. 155 видов Phylinae и 29793 экз. 414 видов Orthotylinae в коллекции ЗИН. 


\section{Видовое разнообразие и степень изученности отдельных регионов}

С помощью данных, извлеченных из базы АЕC, можно оценить степень изученности видового разнообразия разных стран и регионов. Мы ограничили наш анализ странами, материал из которых хорошо представлен в коллекции ЗИН (в общей сложности более 67000 экземпляров); это Россия, Монголия, Казахстан, страны Средней Азии и Закавказья. Соотношение числа экземпляров в коллекции, мест сбора и видов для каждой из этих стран представлено на рис. 8-10.

На всех графиках Россия ожидаемо представлена наибольшим количеством данных, Казахстан и Монголия занимают соответственно второе и третье места. Позиции некоторых стран на графиках сильно различаются. К примеру, Таджикистан находится на четвертом месте по числу экземпляров (рис. 8), но занимает только шестое место по количеству мест сбора (рис. 9) и седьмое место по числу видов (рис. 10). Туркмения находится ближе к концу по количеству экземпляров и мест сбора (рис. 8, 9), но занимает третье место по числу видов (рис. 10).

Phylinae и Orthotylinae особенно разнообразны в странах со средиземноморским типом климата, степях, полупустынях и пустынях (Cassis, Schuh, 2012). Биомы этих типов преобладают в Казахстане, Монголии, Узбекистане и Туркмении, что объясняет значительное видовое разнообразие фаун этих стран. Таджикистан и страны Закавказья меньше по площади, большую часть их территорий занимают горные системы, чем объясняется меньшее число собранных там видов. Фауна России закономерно уступает фауне Средней Азии по числу видов (365 видов в России и 412 - в Средней Азии), несмотря на несравнимо бо́льшие территорию и число собранных экземпляров.

Сопоставление разных административных единиц России по этим же параметрам (рис. 11-13) демонстрирует прежде всего исторически обусловленную неравномерность в пополнении фондовой коллекции ЗИН и может служить непрямой иллюстрацией степени изученности отдельных регионов. Самый большой материал собран в Ленинградской обл., Якутии, Приморском крае, на Сахалине, в Республике Алтай, Иркутской и Амурской областях, Дагестане (рис. 11). Общее число экземпляров из этих регионов составляет половину всей коллекции Phylinae и Orthotylinae ЗИН из России. Сборы из многих регионов незначительны; например, из Смоленской, Орловской, Калужской, Калининградской областей и Республики Мари-Эл есть менее чем по 10 экз. (рис. 11). Наибольшим числом мест сбора представлены Якутия, Ленинградская обл., Приморский край, Сахалин и Иркутская обл. (рис. 12). Общее число мест сборов из этих регионов составляет примерно треть всего числа сборов по России, что стало результатом многолетних кропотливых исследований советских и российских энтомологов В. В. Бианки (Ленинградская обл. и Якутия), А. Н. Кириченко (Ленинградская и Иркутская области, Приморский край), И. М. Кержнера (Республика Алтай, Иркутская обл., Приморский край, Сахалин) и Н. Н. Винокурова (Якутия).

В коллекции ЗИН с территории России представлено 368 видов клопов-слепняков подсемейств Phylinae и Orthotylinae. Больше всего видов собрано в Приморском крае (104), Дагестане (94), Краснодарском крае (85), Якутии (77) и Ленинградской обл. (75) (рис. 13). В первых двух регионах в общей сложности собрано более половины всех видов. Приморский край имеет много общего с флорой и фауной богатой видами Восточной Азии (Безбородов, 2014; Кожевников, Кожевникова, 2014), что определяет значительное видовое разнообразие и эндемизм этого региона. Отсюда известно значительное число видов, относящихся к редким или не встречающимся в других регионах 

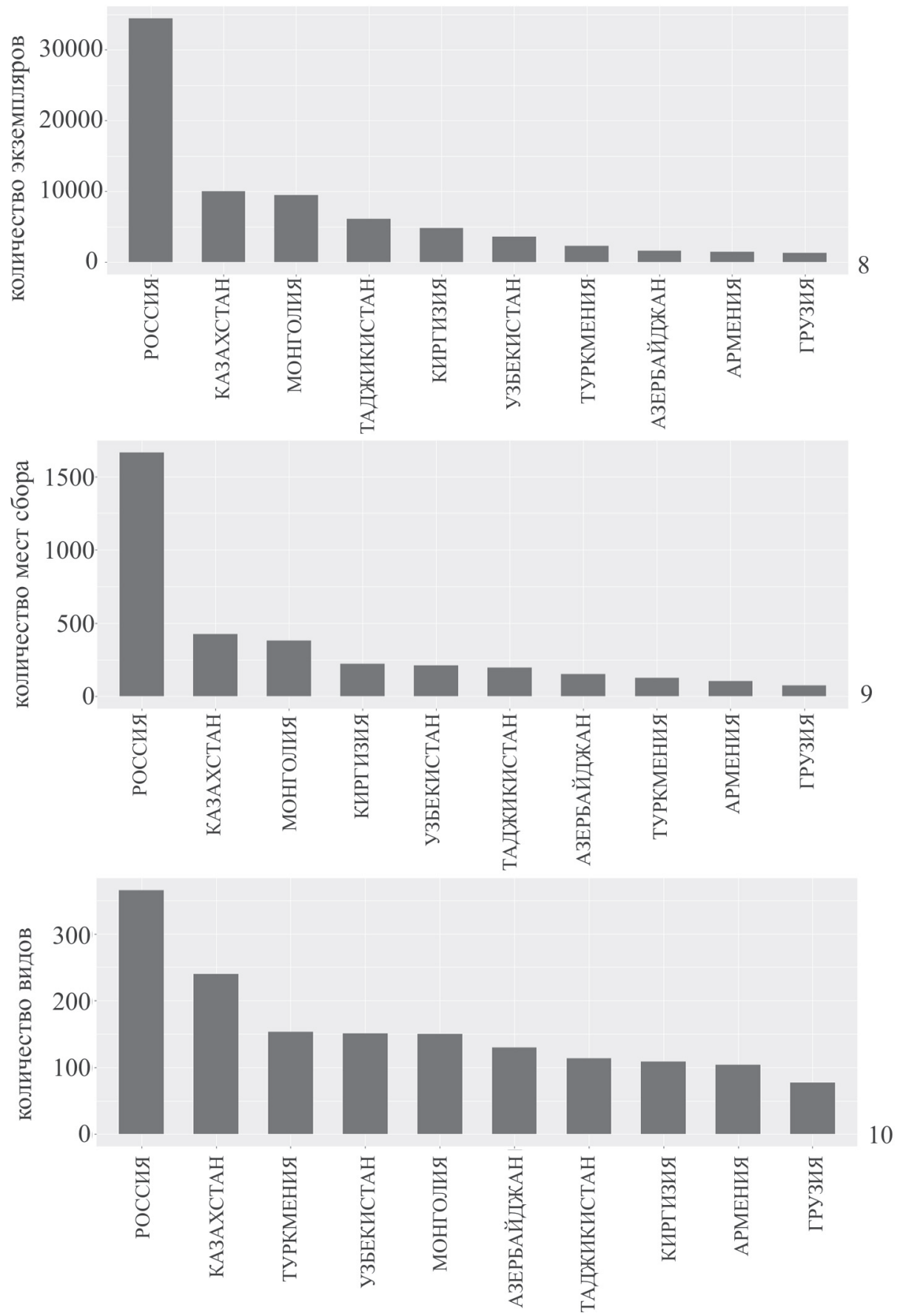

Рис. 8-10. Распределение количества экземпляров, мест сбора и видов подсемейств Phylinae и Orthotylinae для России, Казахстана, Монголии, стран Средней Азии и Закавказья. 8 - количество экземпляров, 9 - количество мест сбора, 10 - количество видов. 

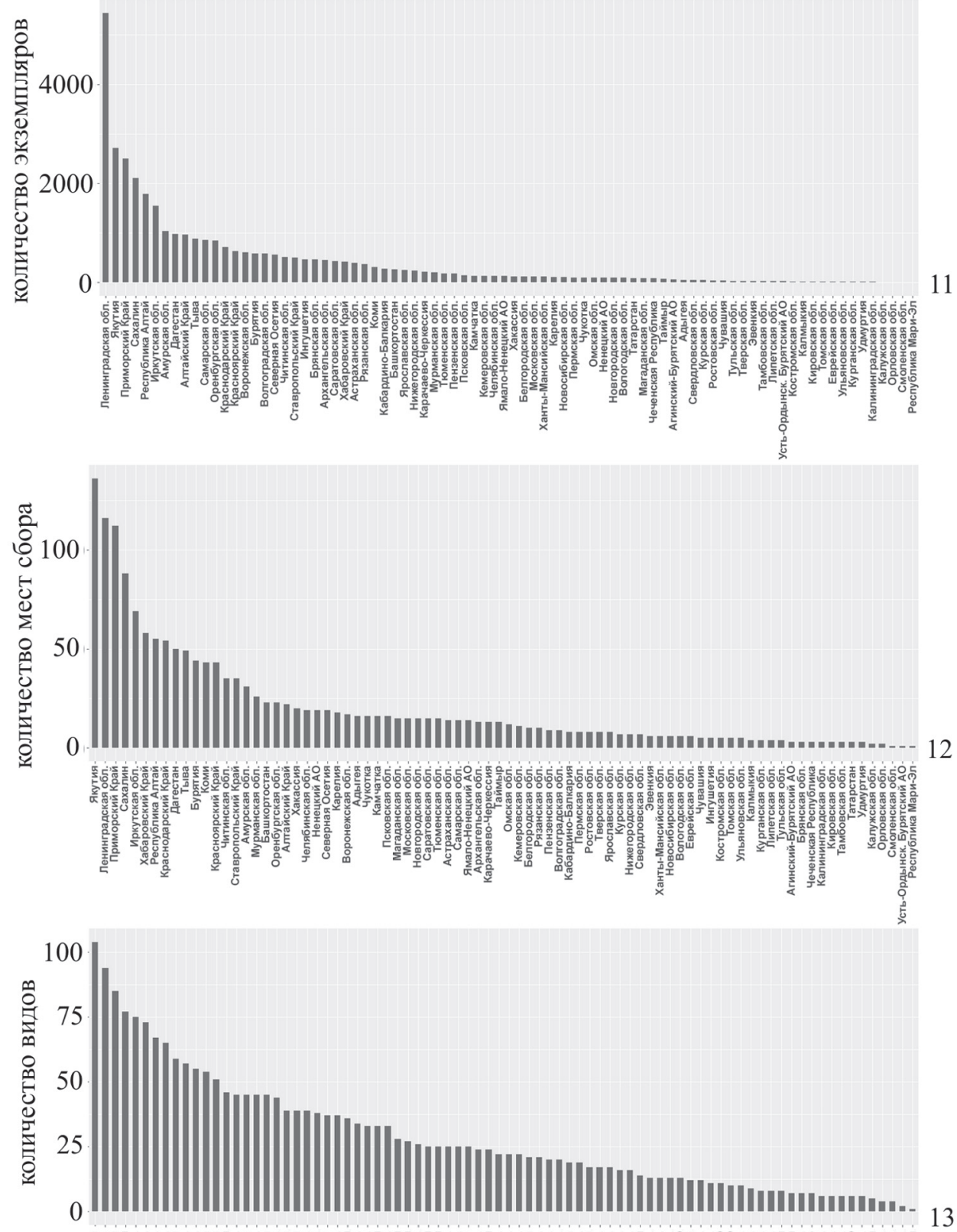

Рис. 11-13. Распределение числа экземпляров, мест сбора и видов подсемейств Phylinae и Orthotylinae для регионов России.

1 - число экземпляров, 12 -мест сбора, 13 -видов. 
Палеарктики родам и трибам (Štys, 1985; Кержнер, 1988; Yasunaga, 2000; Namyatova, Cassis, 2016c). Северный Кавказ и, в частности, Дагестан и Краснодарский край, отличают сочетание умеренного и субтропического типов климата и высокое разнообразие ландшафтов, что предопределяет богатство фауны этого региона (Солодовников, 1998; Прокин и др., 2008). Довольно большое число собранных в Якутии и Ленинградской обл. видов прежде всего объясняется интенсивностью проведенных там сборов.

\section{Кормовые связи}

Насекомые-фитофаги составляют не менее четверти всех описанных видов животных и растений, что определяет важность поиска закономерностей их связей с растениями (Jaenike, 1990; Ødegaard et al., 2005; Janz et al., 2006; Forister et al., 2015).

Несмотря на то, что клопы-слепняки по преимуществу фитофаги, исследования их связей с кормовыми растениями немногочисленны. Пищевая специализация всех подсемейств и подробное обсуждение вредителей приведены в обобщающей монографии по биологии Miridae (Wheeler, 2001). Обзоры связей с кормовыми растениями опубликованы по подсемействам Bryocorinae (Konstantinov et al., 2018) и Isometopinae (Namyatova, Cassis, 2016d), хотя последние - хищники, и их связь с растениями не связана напрямую с кормовыми предпочтениями. Кассис и Шу (Cassis, Schuh, 2012) дали обзор кормовых растений для мировой фауны сем. Miridae, основываясь на данных интернет-каталога (Schuh, 2002-2013), в который внесены библиографические ссылки для всех видов этого семейства, включая многие данные по кормовым растениям. Ими было продемонстрировано, что виды Miridae чаще всего связаны с кладой розид и еe порядками Caryophyllales, Fabales, Fagales и Rosales, а также с кладой астерид и eе порядками Lamiales и Asterales. При этом виды подсем. Phylinae связаны преимущественно с растениями из порядков Caryophyllales, Fagales и Pinales, а виды подсем. Orthotylinae - c Asterales, Fabales и Fagales.

Основываясь на данных базы AЕC и системе семенных растений APG IV (Chase et al., 2016), мы провели сходный анализ для подсемейств Phylinae (589 видов с данными по кормовым растениям) и Orthotylinae (71 вид с данными по кормовым растениям) фауны Палеарктики. В соответствии с полученными данными, виды Phylinae преимущественно связаны с растениями из порядков Caryophyllales (133 вида), Asterales (77), Rosales (70), Fagales (63), Fabales (63) и Pinales (44) (рис. 14). При этом кормовые растения $50 \%$ видов относятся к семействам Asteraceae (Asterales), Amaranthaceae (Caryophyllales), Fabaceae (Fabales), Fagaceae (Fagales), Pinaceae (Pinales) и Rosaceae (Rosales) (рис. 15). Кормовые растения Orthotylinae преимущественно относятся к порядкам Asterales (19 видов), Poales (15), Rosales (15), Malpighiales (14), Caryophyllales (9), Fabales (8) и Fagales (4) (рис. 16). На уровне семейств, 50 \% видов Orthotylinae были отмечены с Asteraceae (Asterales), Salicaceae (Malpighiales), Poaceae (Poales) и Rosaceae (Rosales) (рис. 17).

Наши результаты лишь отчасти соответствуют ранее опубликованным данным (Cassis, Schuh, 2012). В обоих случаях большинство видов зарегистрировано с клад астерид и розид, но это большие группы, которые вместе составляют по крайней мере четверть всех описанных видов растений (Scotland, Wortley, 2003; Wang et al., 2009; Bremer, 2009). Отличия в кормовых связях подсем. Orthotylinae, по-видимому, в большей степени определяются относительно небольшой выборкой видов с установленными кормовыми связями в нашем исследовании, а не спецификой палеарктических 

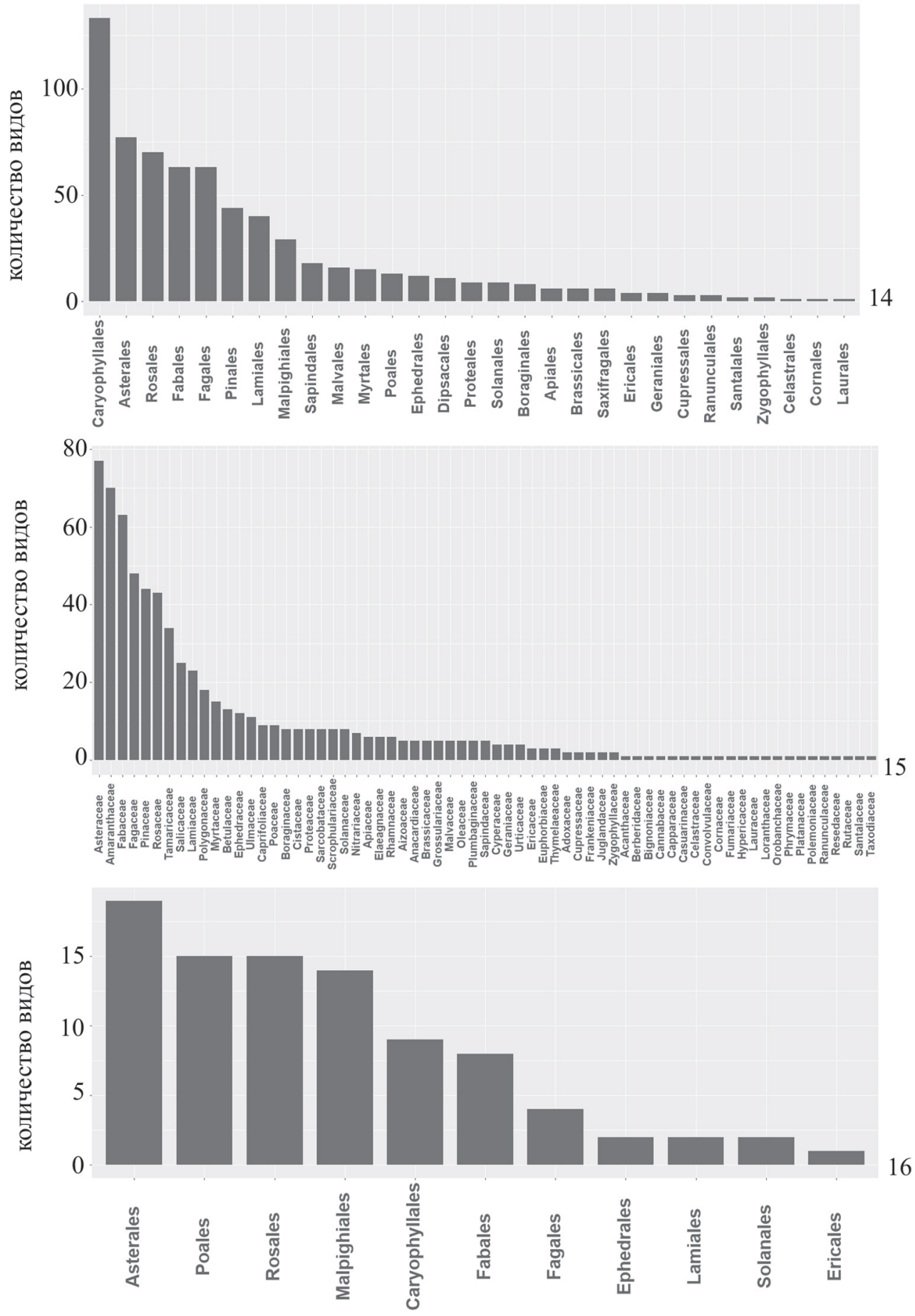

Рис. 14-16. Пищевая специализация клопов подсемейств Phylinae и Orthotylinae.

14 - специализация Phylinae к порядкам растений, 15 - специализация Phylinae к семействам растений, 16 - специализация Orthotylinae к порядкам растений. 

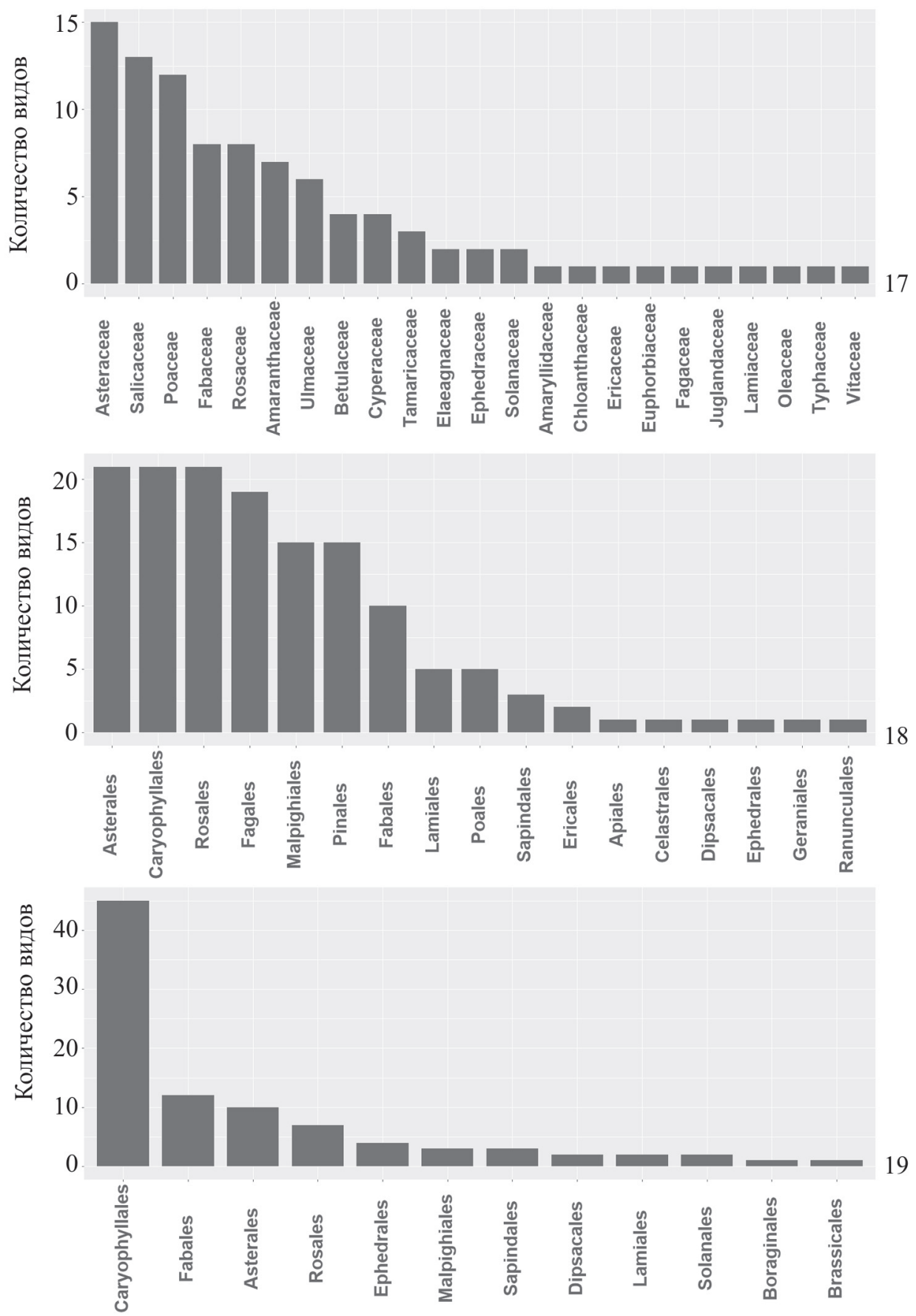

Рис. 17-19. Пищевые связи клопов подсемейств Phylinae и Orthotylinae.

7 - специализация к семействам растений видов подсем. Orthotylinae Палеарктики, 18 - специализация к порядкам растений видов подсем. Phylinae на территории России, 19 - специализация к порядкам растений видов подсем. Phylinae на территории Казахстана. 
фауны и флоры. Напротив, данные по кормовым связям подсем. Phylinae хорошо представлены в нашем наборе. Пищевые связи видов подсемейства определяются многими факторами и сильно различаются в пределах Палеарктики, что может быть проиллюстрировано сравнением их у видов из стран, хорошо представленных в анализируемом наборе данных (Россия, Монголия, Казахстан).

Почти равное число видов подсем. Phylinae России специализируется на растениях из порядков Asterales, Caryophyllales и Rosales, затем идут Fagales, Malpighiales и Pinales (рис. 18). В Казахстане и Монголии наибольшее число видов обитает на растениях порядка Caryophyllales, за ним следуют Fabales, Asterales и Rosales, причем с последних трех групп растений было отмечено гораздо меньше видов (рис. 19, 20). Распределение по семействам показывает, что для Казахстана и России порядок Caryophyllales является самым предпочитаемым в основном за счет сем. Amaranthaceae (включающего маревые в качестве подсем. Chenopodioideae), а для Монголии - за счет Amaranthaceae и Tamaricaceae. Преобладание Phylinae в Монголии и Казахстане на растениях порядка Caryophyllales объясняется обилием видов Amaranthaceae и Tamaricaceae в Средней и Центральной Азии и тесными связями многих родов Phylinae с растениями этих групп (Kment, Brija, 2007; Konstantinov, 2008a, 2008b; Matocq, 2011).

Многие виды во всех трех странах связаны с порядками Asterales и Rosales, прежде всего за счет больших семейств Asteraceae и Rosaceae, хорошо представленных как в России, так и в более южных азиатских странах (Ryabushkina et al., 2008; Urgamal et al., 2013). Среди кормовых растений из сем. Asteraceae значительно преобладают полыни (Artemisia spp.). В Казахстане и Монголии немало видов связано с растениями порядка Fabales, в то время как для видов с территории России этот порядок находится только на седьмом месте. В основном виды Phylinae были отмечены с рода Caragana, который гораздо лучше представлен в полупустынях и пустынях Центральной Азии, чем в России (Zhang et al., 2009). В отличие от результатов по России, в Казахстане виды Phylinae не отмечены с Pinales, а в Монголии лишь несколько видов отмечены с представителей этого порядка. Это отражает ограниченное распространение биомов смешанных и хвойных лесов в Средней и Центральной Азии.

Среди насекомых часты случаи специализации на одном виде растений (Janz et al., 2001; Peccoud et al., 2010; Winkler, Mitter, 2008), представителях одного рода или семейства (Novotny et al., 2002; Ødegaard et al., 2005). Сказанное в полной мере справедливо и для представителей сем. Miridae. Согласно данным Кассиса и Шу, около 60 \% видов слепняков отмечено только с одного вида растений (Cassis, Schuh, 2012), при этом для многих видов установлена связь с отдельным родом или семейством растений (Namyatova, Cassis, 2013; Konstantinov et al., 2018; Symonds, Cassis, 2018).

Мы оценили степень специализации палеарктических видов Phylinae и Orthotylinae на основе материала фондовой коллекции ЗИН. Результаты обработки всего набора данных по двум подсемействам показывают высокую степень специализации. Около 75 \% видов филин и ортотилин - монофаги, отмеченные лишь с одного вида растений (рис. 21). При этом число видов, ограниченных в кормовых связях одним семейством растений, достигает 85 \% (рис. 22). Расчеты, выполненные для видов подсемейств Phylinae и Orthotylinae порознь, показывают примерно такие же процентные соотношения. 

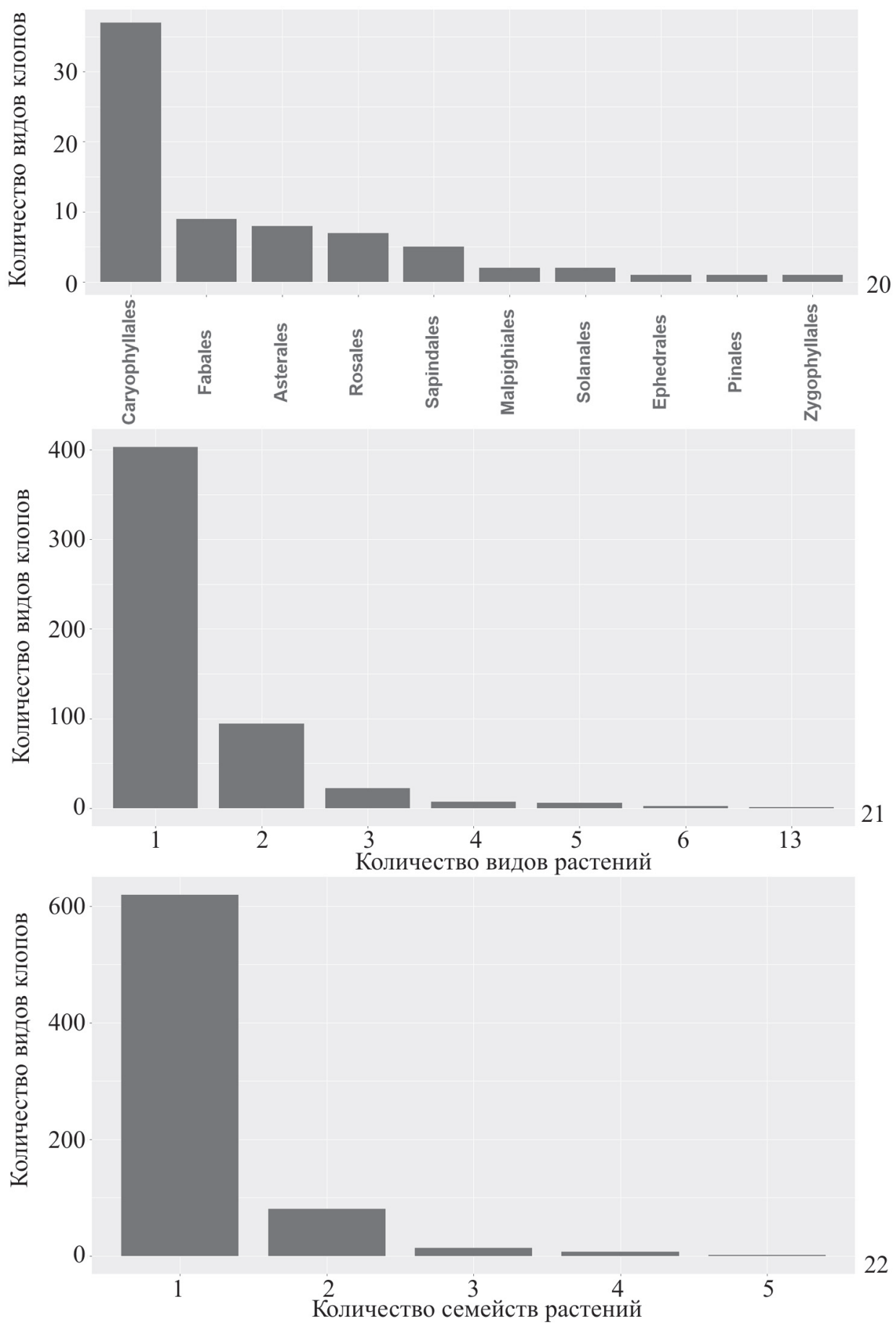

Рис. 20-22. Пищевые связи клопов подсемейств Phylinae и Orthotylinae.

20 - специализация Phylinae к порядкам растений на территории Монголии, 21 - специализация Phylinae и Orthotylinae к видам растений, 22 - специализация Phylinae и Orthotylinae к семействам растений. 
Таким образом, материалы интернет-доступной базы данных АЕС могут служить основой для первичного анализа распространения видов и их специализации на определенных кормовых растениях. Эти сведения можно также использовать для биогеографических исследований, изучения коэволюции слепняков с растениями, а также анализа фаун отдельных регионов.

\section{БЛАГОДАРНОСТИ}

Описанные в данной работе методы и подходы сформировались в рамках проекта Национального научного фонда США «Инвентаризация биоразнообразия планеты» (Planetary Biodiversity Inventory, PBI), посвященного исследованию сем. Miridae. В ходе выполнения этого проекта (DEB 0316495 to R. T. Schuh, G. Cassis) была создана и база данных AEC. Мы искренне признательны многим коллегам, в первую очередь P. T. Шу (R. T. Schuh), Г. Кассису (G. Cassis), М. Шварцу (M. Schwartz), К. Вейраух (C. Weirauch) за совместную работу, многолетнюю помощь и плодотворные обсуждения.

\section{ФИНАНСИРОВАНИЕ}

Работа выполнена в рамках темы госзадания АААА-А19-119020690101-6 и поддержана грантом Российского фонда фундаментальных исследований № 19-04-00662.

\section{СПИСОК ЛИТЕРАТУРЫ}

Безбородов В. Г. 2014. Аннотированный список пластинчатоусых жуков (Coleoptera, Scarabaeoidea) фауны Приморского края (Россия). Амурский зоологический журнал 6 (1): 22-50.

Кержнер И. М. 1988. Новые и малоизвестные полужесткокрылые насекомые (Heteroptera) с Дальнего Востока СССР. Владивосток: ДВНЦ АН СССР, с. 87.

Кожевников А. Е., Кожевникова 3. В. 2014. Таксономический состав и особенности природной флоры Приморского края. Комаровские чтения 62: 7-62.

Прокин А. А., Шаповалов М. И., Сапрыкин М. А. 2008. Водные полужесткокрылые и водомерки (Heteroptera: Nepomorpha, Gerromorpha) Северо-Западного Кавказа: обзор фауны и ее зоогеографические особенности. Кавказский энтомологический бюллетень 4 (3): 261-271.

Солодовников А. Ю. 1998. Фауна стафилинид (Coleoptera, Staphylinidae) Северо-Западного Кавказа. Подсемейства Staphylininae, Xantholininae, Paederinae, Steninae, Oxуроrinae. Энтомологическое обозрение 77 (2): $331-354$.

Allan E. L., Livermore L., Price B. W., Shchedrina O., Smith V. S. 2019. A novel automated mass digitisation workflow for natural history microscope slides. Biodiversity data journal 7: e32342.

Ang Y., Puniamoorthy J., Pont A. C., Bartak M., Blanckenhorn W. U., Eberhard W. G., Puniamoorthy N., Silva V. C., Munari L., Meier R. 2013. A plea for digital reference collections and other science-based digitization initiatives in taxonomy: Sepsidnet as exemplar. Systematic Entomology 38 (3): 637-644.

Ariño A. 2010. Approaches to estimating the universe of natural history collections data. Biodiversity Informatics 7 (2): 81-92.

Beaman R. S., Cellinese N. 2012. Mass digitization of scientific collections: New opportunities to transform the use of biological specimens and underwrite biodiversity science. ZooKeys 209: 7-17.

Bertone M., Blinn R., Stanfield T., Dew K., Seltmann K., Deans A. 2012. Results and insights from the NCSU Insect Museum GigaPan project. ZooKeys 209: 115-132.

Bik H. M. 2017. Let's rise up to unite taxonomy and technology. PLOS Biology 15 (8): e2002231.

Blagoderov V., Kitching I. J., Livermore L., Simonsen T. J., Smith V. S. 2012. No specimen left behind: industrial scale digitization of natural history collections. ZooKeys 209: 133-146.

Bremer B. 2009. Asterids. In: S. Kumar, S. B. Hedges (eds). Timetree of Life. OUP Oxford, pp. 177-187.

Cassis G., Schuh R. T. 2012. Systematics, biodiversity, biogeography, and host associations of the Miridae (Insecta: Hemiptera: Heteroptera: Cimicomorpha). Annual Review of Entomology 57: 377-404.

Cassis G., Wall M. A., Schuh R. T. 2007. Insect biodiversity and industrializing the taxonomic process: A case study with the Miridae (Heteroptera). In: T. Hodkinson, J. Parnell (eds). Towards the Tree of Life: Taxonomy and Systematics of Large and Species Rich Clades. Boca Raton: CRC Press, pp. 193-212. 
Chase M. W., Christenhusz M. J. M., Fay M. F., Byng J. W., Judd W. S., Soltis D. E., Mabberley D. J., Sennikov A. N., Soltis P. S., Stevens P. F. 2016. An update of the Angiosperm Phylogeny Group classification for the orders and families of flowering plants: APG IV. Botanical Journal of the Linnean Society 181 (1): $1-20$.

Clark B. R., Godfray H. C. J., Kitching I. J., Mayo S. J., Scoble M. J. 2008. Taxonomy as an eScience. Philosophical Transactions of the Royal Society A: Mathematical, Physical and Engineering Sciences 367 (1890): 953-966.

Forister M. L., Novotny V., Panorska A. K., Baje L., Basset Y., Butterill P. T., Cizek L., Coley P. D., Dem F., Diniz I. R., Drozd P., Fox M., Glassmire A. E., Hazen R., Hrcek J., Jahner J. P., Kaman O., Kozubowski T. J., Kursar T. A., Lewis O. T., Lill J., Marquis R. J., Miller S. E., Morais H. C., Murakami M., Nickel H., Pardikes N. A., Ricklefs R. E., Singer M. S., Smilanich A. M., Stireman J. O., Villamarín-Cortez S., Vodka S., Volf M., Wagner D. L., Walla T., Weiblen G. D., Dyer L. A. 2015. The global distribution of diet breadth in insect herbivores. Proceedings of the National Academy of Sciences of the United States of America 112 (2): 442-447.

Funk V. A. 2018. Collections-based science in the 21st Century. Journal of Systematics and Evolution 56: $175-193$.

Goodwin Z. A., Harris D. J., Filer D., Wood J. R., Scotland R. W. 2015. Widespread mistaken identity in tropical plant collections. Current Biology 25 (22): R1066-R1067.

Hudson L. N., Blagoderov V., Heaton A., Holtzhausen P., Livermore L., Price B. W., van der Walt S., Smith V. S. 2015. Inselect: Automating the Digitization of Natural History Collections. PLOS One 10 (11): e0143402.

Jaenike J. 1990. Host specialization in phytophagous insects. Annual Review of Ecology and Systematics 21 (1): 243-273.

Janz N., Nyblom K., Nylin S. 2001. Evolutionary dynamics of host plant specialization: a case study of the tribe Nymphalini. Evolution 55 (4): 783-796.

Janz N., Nylin S., Wahlberg N. 2006. Diversity begets diversity: host expansions and the diversification of plantfeeding insects. BMC Evolutionary Biology 6 (1): 4.

Johnson N. F. 2007. Biodiversity informatics. Annual Review of Entomology 52: 421-438.

Kerzhner I. M., Josifov M. 1999. Miridae. In: B. Aukema, C. Rieger (eds.) Catalogue of the Heteroptera of the Palaearctic Region. Vol. 3. Amsterdam: The Netherlands Entomological Society, 577 p.

Kment P., Bryja J. 2007. Description of Nasocoris lautereri sp. nov. from the Balkan peninsula, with a review of the genus Nasocoris (Hemiptera: Heteroptera: Miridae: Phylinae). Zootaxa 1633 (1): 39-61.

Knyshov A. A., Konstantinov F. V. 2012. A new genus and species of the tribe Orthotylini (Heteroptera: Miridae: Orthotylinae) from Central Asia. European Journal of Entomology 109 (1): 117-128.

Knyshov A. A., Konstantinov F. V. 2013a. A taxonomic revision of the genus Platycranus Fieber, 1870 (Hemiptera: Heteroptera: Miridae: Orthotylinae). Zootaxa 3637 (2): 201-253.

Knyshov A. A., Konstantinov F. V. 2013b. A taxonomic revision of the genus Hyoidea (Hemiptera: Heteroptera: Miridae). Acta Entomologica Musei Nationalis Pragae 53 (1): 1-32.

Konstantinov F. V. 2008a. Review of the genus Camptotylus Fieber, 1860 (Heteroptera: Miridae) with description of two new species. American Museum Novitates 3606: 1-23.

Konstantinov F. V. 2008b. Review of Solenoxyphus Reuter, 1875 (Heteroptera: Miridae: Phylinae). American Museum Novitates 3607: 1-44.

Konstantinov F. V. 2008c. Review of Omocoris Lindberg, 1930 and a description of a new genus to accommodate Eurycolpus dimorphus Wagner, 1961 (Heteroptera: Miridae: Phylinae): In: S. Grozeva, N. Simov (eds.) Advances in Heteroptera Research. Festschrift in Honour of 80th Anniversary of Michail Josifov. SofiaMoscow: Pensoft Publishers, pp. 165-180.

Konstantinov F. V. 2008d. Review of Ethelastia Reuter (Heteroptera: Miridae: Phylinae). Insect Systematic and Evolution 39: 213-222.

Konstantinov F. V. 2008e. Revision of Phaeochiton Kerzhner, 1964 (Heteroptera: Miridae: Phylini). European Journal of Entomology 105: 771-781.

Konstantinov F. V. 2016. New synonymies in the plant bug family Miridae (Hemiptera: Heteroptera) from Northern China. Zootaxa 4205 (5): 496-500.

Konstantinov F. V. 2019. Revision of Agraptocoris Reuter (Heteroptera: Miridae: Phylinae), with description of five new species and a review of aedeagal terminology. Arthropod Systematics \& Phylogeny 77 (1): 89-126.

Konstantinov F. V., Knyshov A. A. 2015. The tribe Bryocorini (Insecta: Heteroptera: Miridae: Bryocorinae): phylogeny, description of a new genus, and adaptive radiation on ferns. Zoological Journal of the Linnean Society 175: 441-472.

Konstantinov F. V., Korzeev A. I. 2014. Solenoxyphus Reuter, 1875 (Hemiptera: Heteroptera: Miridae: Phylinae): revised diagnosis, a new species and new generic synonym. Zootaxa 3860 (5): 464-478. 
Konstantinov F. V., Luo Z., Vinokurov N. N. 2013. Two new species, new synonymies, and new records of plant bugs (Hemiptera: Heteroptera: Miridae) from Northwestern China. Zootaxa 3666 (2): 203-220.

Konstantinov F. V., Namyatova A. A. 2008. New records of Phylinae (Hemiptera: Heteroptera: Miridae) from the Palaearctic Region. Zootaxa 1870: 24-42.

Konstantinov F. V., Namyatova A. A. 2009. New records of Orthotylinae (Hemiptera: Heteroptera: Miridae) from the Palaearctic Region. Zootaxa 2295: 55-63.

Konstantinov F. V., Namyatova A. A., Cassis G. 2018. A synopsis of the bryocorine tribes (Heteroptera: Miridae: Bryocorinae): key, diagnoses, hosts and distributional patterns. Invertebrate Systematics 32 (4): 864-889.

Konstantinov F. V., Neimorovets V. V., Korzeev A. I. 2015. The genus Campylomma Reuter, 1878 (Hemiptera: Heteroptera: Miridae: Phylinae): two new synonyms and discussion of the diagnosis. Zootaxa 3974 (2): 203-216.

Konstantinov F. V., Neimorovets V. V., Korzeev A. I. 2016. Review of Campylomma from Russia, Caucasus, and Central Asia with description of two new species (Hemiptera: Heteroptera: Miridae: Phylinae). Entomologica Americana 122 (1): 115-155.

Konstantinov F. V., Simov N. 2018. Review of the subgenus Plumiger of Myrmecophyes, with description of a new species (Heteroptera, Miridae, Halticini). ZooKeys 796: 215-239.

Konstantinov F. V., Vinokurov N. N. 2011. New species and new records of Plant Bugs (Hemiptera: Heteroptera) from Northwestern China. Zootaxa 2836: $27-43$.

Mantle B. L., La Salle J., Fisher N. 2012. Whole-drawer imaging for digital management and curation of a large entomological collection. ZooKeys 209: 147-163.

Matocq A. 2011. Una nueva especie de Nasocoris de Marruecos (Hemiptera: Heteroptera: Miridae: Phylinae). Heteropterus Revista de Entomología 11 (2): 299-304.

Meier R., Dikow T. 2004. Significance of specimen databases from taxonomic revisions for estimating and mapping the global species diversity of invertebrates and repatriating reliable specimen data. Conservation Biology 8 (2): $478-488$.

Miller J., Dikow T., Agosti D., Sautter G., Catapano T., Penev L., Zhang Z., Pentcheff D., Pyle R., Blum S., Parr C. 2012. From taxonomic literature to cybertaxonomic content. BMC Biology 10 (1): 87.

Miller J. A., Miller J. H., Pham D. S., Beentjes K. K. 2014. Cyberdiversity: improving the informatic value of diverse tropical arthropod inventories. PloS One 9 (12): e115750.

Namyatova A. A. 2010. Revision of the genus Pachytomella (Heteroptera: Miridae: Orthotylinae: Halticini). Acta Entomologica Musei Nationalis Pragae 50 (2): 341-368.

Namyatova A. A., Cassis G. 2013. Systematics, phylogeny and host associations of the Australian endemic monaloniine genus Rayieria Odhiambo (Insecta: Heteroptera: Miridae: Bryocorinae). Invertebrate Systematics 27 (6): 689-726.

Namyatova A. A., Cassis G. 2016a. Revision and phylogeny of the fern-inhabiting genus Felisacus Distant (Insecta: Heteroptera: Miridae: Bryocorinae). Bulletin of the American Museum of Natural History 403: 1-168.

Namyatova A. A., Cassis G. 2016b. A remarkable new genus and six new species of fern-inhabiting plant bugs endemic to the Society Islands (Insecta: Heteroptera: Miridae: Mirinae: Filicicoris gen. nov.). Insect Systematics \& Evolution 47 (3): 285-312.

Namyatova A. A., Cassis G. 2016c. Systematic revision and phylogeny of the plant bug tribe Monaloniini (Insecta: Heteroptera: Miridae: Bryocorinae) of the world. Zoological Journal of the Linnean Society 176 (1): 36-136.

Namyatova A. A., Cassis G. 2016d. Review of the seven new species of Isometopinae (Heteroptera: Miridae) in Australia and discussion of distribution and host plant associations of the subfamily on a worldwide basis. Austral Entomology 55 (4): 392-422.

Namyatova A. A., Cassis G. 2019. First record of the subfamily Psallopinae (Heteroptera: Miridae) from Australia and discussion of its systematic position and diagnostic characters. Austral Entomology 58 (1): 156-170.

Namyatova A. A., Contos P., Cassis G. 2019. New species, taxonomy, phylogeny, and distribution of the tropical tribe Bothriomirini (Insecta: Heteroptera: Miridae: Cylapinae). Insect Systematics \& Evolution 50 (1): 1-64.

Namyatova A. A., Konstantinov F. V. 2009. Revision of the genus Orthocephalus Fieber, 1858 (Hemiptera: Heteroptera: Miridae: Orthotylinae). Zootaxa 2316: 1-118.

Namyatova A. A., Konstantinov F. V., Cassis G. 2016. Phylogeny and systematics of the subfamily Bryocorinae based on morphology with emphasis on the tribe Dicyphini sensu Schuh. Systematic Entomology 41 (1): $3-40$.

Novotny V., Miller S. E., Basset Y., Cizek L., Drozd P., Darrow K., Leps J. 2002. Predictably simple: assemblages of caterpillars (Lepidoptera) feeding on rainforest trees in Papua New Guinea. Proceedings of the Royal Society of London. Series B: Biological Sciences 269 (1507): 2337-2344.

Ødegaard F., Diserud O. H., Østbye K. 2005. The importance of plant relatedness for host utilization among phytophagous insects. Ecology Letters 8 (6): 612-617. 
Peccoud J., Simon J. C., von Dohlen C., Coeur d'acier A., Plantegenest M., Vanlerberghe-Masutti F., Jousselin E. 2010. Evolutionary history of aphid-plant associations and their role in aphid diversification. Comptes Rendus Biologies 333 (6-7): 474-487.

Peterson A. T., Knapp S., Guralnick R., Soberón J., Holder M. T. 2010. The big questions for biodiversity informatics. Systematics and Biodiversity 8 (2): 159-168.

Ryabushkina N., Gemedjieva N., Kobaisy M., Cantrell C. L. 2008. Brief review of Kazakhstan flora and use of its wild species. The Asian and Australian Journal of Plant Science and Biotechnology 2 (2): 64-71.

Schuh R. T. 1995. Plant Bugs of the World (Insecta, Heteroptera, Miridae). New York: New York Entomological Society, p. 1329.

Schuh R. T. 2001. Revision of New World Plagiognathus Fieber, with comments on the Palearctic fauna and the description of a new genus (Heteroptera: Miridae: Phylinae). Bulletin of the American Museum of Natural History 266: 1-267.

Schuh R. T. 2012. Integrating specimen databases and revisionary systematics. ZooKeys 209: 255-267.

Schuh R. T. [Интернет документ] 2002-2013. On-line systematic catalog of plant bugs (Insecta: Heteroptera: Miridae) [URL: http:// research.amnh.org/pbi/catalog/]

Schuh R. T., Lindskog P., Kerzhner I. M. 1995. Europiella Reuter (Heteroptera: Miridae): recognition as a Holarctic group, notes on synonymy, and description of a new species, Europiella carvalhoi, from North America. Proceedings of the Entomological Society of Washington 97: 379-395.

Schuh R. T., Hewson-Smith S., Ascher J. S. 2010. Specimen databases: A case study in entomology using Webbased software. American Entomologist 56: 206-216.

Scotland R. W., Wortley A. H. 2003. How many species of seed plants are there? Taxon 52 (1): 101-104.

Short A. E. Z., Dikow T., Moreau C. S. 2018. Entomological collections in the age of big data. Annual Review of Entomology 63: 513-530.

Sikes D. S., Copas K., Hirsch T., Longino J. T., Schigel D. 2016. On natural history collections, digitized and not: a response to Ferro and Flick. ZooKeys 618: 145-158.

Soltis D. E., Soltis P. S. 2016. Mobilizing and integrating big data in studies of spatial and phylogenetic patterns of biodiversity. Plant Diversity 38 (6): 264-270.

Ströbel B., Schmelzle S., Blüthgen N., Heethoff M. 2018. An automated device for the digitization and 3D modelling of insects, combining extended-depth-of-field and all-side multi-view imaging. ZooKeys 759: 1-27.

Štys P. 1985. New genus of Palaearctic Bryocorinae related to Afrotropical Rhodocoris (Heteroptera, Miridae). Acta Entomologica Bohemoslovaca 82: 407-425.

Symonds C. L., Cassis G. 2018. Systematics and analysis of the radiation of Orthotylini plant bugs associated with Callitroid conifers in Australia: Description of five new genera and 32 new species (Heteroptera: Miridae: Orthotylinae). Bulletin of the American Museum of Natural History 2018 (422): 1-227.

Urgamal M., Oyuntsetseg B., Nyambayar D. 2013. Synopsis and recent additions to the flora of Mongolia. Proceedings of the Mongolian Academy of Sciences 25: 53-72.

Vollmar A., Macklin J. A., Ford L. 2010. Natural history specimen digitization: challenges and concerns. Biodiversity Informatics 7 (2): 93-112.

Wang H., Moore M. J., Soltis P. S., Bell C. D., Brockington S. F., Alexandre R., Davis C. C., Latvis M., Manchester S. R., Soltis D. E. 2009. Rosid radiation and the rapid rise of angiosperm-dominated forests. Proceedings of the National Academy of Sciences 106 (10): 3853-3858.

Wen J., Ickert-Bond S. M., Appelhans M. S., Dorr L. J., Funk V. A. 2015. Collections-based systematics: Opportunities and outlook for 2050. Journal of Systematics and Evolution 53 (6): 477-488.

Wheeler, A. G. 2001. Biology of the plant bugs (Hemiptera: Miridae): pests, predators, opportunists. Ithaca and London: Cornell University Press, p. 507.

Wheeler Q. D. 2007. Invertebrate systematics or spineless taxonomy? Zootaxa 1668 (1): 11-18.

Winkler I. S., Mitter C. 2008. The phylogenetic dimension of insect-plant interactions: a review of recent evidence. In: K. Tilmon (ed.). Specialization, Speciation, and Radiation: the Evolutionary Biology of Herbivorous Insects. Oakland, Calfornia: University of California Press, pp. 240-263.

Yasunaga T. 2000. The mirid subfamily Cylapinae (Heteroptera: Miridae), or fungal inhabiting plant bugs in Japan. Tijdschrift voor Entomologie 143 (1-2): 183-209.

Zhang M., Fritsch P. W., Cruz B. C. 2009. Phylogeny of Caragana (Fabaceae) based on DNA sequence data from rbcL, trnS-trnG, and ITS. Molecular Phylogenetics and Evolution 50 (3): 547-559. 


\title{
TAXONOMIC REVISIONS AND SPECIMEN DATABASES IN THE INTERNET AGE: DEALING WITH A SPECIES RICH INSECT TAXON
}

\author{
F. V. Konstantinov, A. A. Namyatova
}

Key words: databases, entomological collections, systematics, cybertaxonomy, revisions, biogeography, trophic associations.

\section{S U M M A R Y}

World entomological collections were formed during over three centuries of sampling and research. These collections provide the only direct documentation of the distribution and natural history of insects, being integral to our efforts to understand biodiversity. However, a substantial part of the world holdings remains not catalogued and, therefore, inaccessible for comprehensive analysis. Taxonomic revision of any particular plant or animal group implies a detailed synthesis of all available information, a task that may take full advantage of all the new web-based technologies and databases. Arthropod Easy Capture specimen relational database (AEC) provides convenient way for assembling and integrating specimen information. Long-term experience of integration AEC specimen technology into our revisionary project workflows illustrates the benefits of such approach resulting, among other things, in minimization of time required for data-capture, straightforward producing of distributional maps, integration of host data, and offers easy access of other researchers to primary data. The specimen database may also be a powerful tool for biogeography and coevolution studies. 